\title{
ATTENTION DEFICIT DISORDER WITH HYPERACTIVITY (ADDH): THE CONTRIBUTION OF CATECHOLAMINERGIC ACTIVITY
}

\author{
Robert D. OADES \\ Department of Physiology, Flinders University Medical Centre, Bedford Park, S.A. 5042, Australia
}

(Received 28 April 1986)

\section{Contents}

1. Introduction

2. Psychostimulant treatment-neurochemical response $r$\begin{tabular}{lr}
365 \\
\hline
\end{tabular}

$\begin{array}{ll}\text { 2.1. The psychostimulants } & 367\end{array}$

$\begin{array}{ll}\text { 2.2. The neurochemical response } & 367\end{array}$

$\begin{array}{ll}\text { 2.2.1. Catecholamines (CA) } & 367\end{array}$

$\begin{array}{ll}\text { 2.2.2. Serotonin }(5-\mathrm{HT}) & 369\end{array}$

$\begin{array}{ll}\text { 2.3. Electrophysiological indices of cognition } & 370\end{array}$

$\begin{array}{ll}\text { 2.4. Behavioral indices of cognition } & 371\end{array}$

2.5. Responses to other monoaminergic agents $\quad 372$

2.5.1. Precursors (L-DOPA and amino acids)

2.5.2. Monoamine oxidase (MAO) 373

2.5.3. Alternative directions

3. Similarities and differences with other disorders of catecholamines and attentional function 374

3.1. Phenylketonuria $\quad 374$

3.2. Tourette's Syndrome $\quad 375$

3.3. Lesch-Nyhan Syndrome $\quad 375$

4. Parallels to experimental animal studies $\quad 376$

4.1. Attention-related symptoms 376

$\begin{array}{ll}\text { 4.2. Hyperactivity symptoms } & 377\end{array}$

5. An animal model-spontaneous hypertension $\quad 379$

5.1. The spontaneously hypertensive rat (SHR) $\quad 379$

$\begin{array}{ll}\text { 5.2. Neurobiology of hypertension: participation in SHR behavior? } & 379\end{array}$

$\begin{array}{ll}\text { 5.2.1. Noradrenaline (NA) } & 379\end{array}$

$\begin{array}{ll}\text { 5.2.2. Glutamate, neuropeptide } \mathrm{Y} \text { and serotonin } & 380\end{array}$

$\begin{array}{ll}\text { 5.2.3. Dopamine (DA) } & 380\end{array}$

$\begin{array}{ll}\text { 5.3. The link with behavior and cognition } & 381\end{array}$

$\begin{array}{ll}\text { 5.4. The septum? } & 381\end{array}$

\begin{tabular}{lr} 
6. Conclusions & 383 \\
\hline
\end{tabular}

$\begin{array}{lr}\text { 7. Summary } & 383\end{array}$

$\begin{array}{lr}\text { Acknowledgement } & 384\end{array}$

$\begin{array}{lr}\text { References } & 384\end{array}$

\section{Introduction}

From the middle of the nineteenth to halfway through the twentieth century an association between insanity and hyperkinesia was commonly described (Ireland, 1877; Tuke, 1892; Ingram, 1956; Ounsted, 1955). The clinical picture of an attention deficit disorder with hyperkinesia, recognizably similar to that in use today (ADDH), was first widely identified as a common result of Von Economo's encephalitis in children after the first world war ("post-encephalitic disorder"). Currently the diagnostic and statistical manual of the American Psychiatric Association (DSM III, 1980) notes that the primary features of "childhood attention disorder with hyperactivity" are inattention (poor concentration), impulsivity and excessive motor activity (cf also Utah criteria; Wender et al., 1984). In North America this concept, as least in name, replaced the more limited concept denoted by the "hyperactive child syndrome" (Laufer et al., 1957; Stewart et al., 1966). 
Until recently, related diagnoses have been made less frequently in Europe (review, Weiss and Hechtman, 1979; incidence U.S.A. $=3-10 \%$, U.K. $=1.2 \%$; Thorley, 1984). The results of Australian work suggest there is a difference between the diagnostic practice in the U.S.A. and elsewhere which reflects the degree of symptom severity that is accepted as diagnostically significant rather than a categorical difference of incidence in and outside the U.S.A. (Glow, 1984; Glow and Glow, 1980). In practice the emphasis on motor activity in the syndrome has been formally retained (International Classification of Diseases, ICD 9 , WHO, 1978). This probably reflects the history of the association between brain damage and hyperkinesia. However, as Barkley (1982) has emphasized, the American practice is to exclude any overt neurological component. This is fair, as recent computer tomographic studies have failed to find any consistent differences in the brain density, ventricular volumes or ratios of groups of ADDH subjects (Harcherik et al., 1985; Shaywitz et al., 1983).

This review will not consider the dimensions of defiance-aggression and anxiety-fear that appear on some rating scales (cf Conners, 1973; Werry, 1968). Indeed Thorley (1984; also Weiss and Hechtman, 1979) distinguishes an aggressive "conduct disorder" group from a hyperkinetic group with attentional and articulatory disturbances. Even those who emphasize the lack of a clear-cut distinction between ADDH children, adults with a residual symptomatology and groups with related symptoms nevertheless characterize them in a separable manner (e.g. Steinhausen and Goebel, 1985; Table 1). Thus I shall not discuss whether the syndrome of ADDH should and whether the disease entity does include features of conduct disorder. Rather for the purposes of research into the bases of ADDH (and of this article) it is useful to try to isolate a group of subjects primarily showing the symptoms of ADDH alone. This is analogous to similar research strategies that have been advocated for schizophrenia (Taylor and Abrams, 1975; Oades, 1982a). The emphasis here is to establish the separate features of attentional dysfunction and hyperkinesis and evaluate studies of the potential neurobiological concomitants.

Under consideration are children, usually boys (boy:girl ratio 3-9:1, Mannuzza and Gittelman, 1984) aged 5-13 years of whom more than half have shown symptoms for several years before treatment (Weiss and Hechtman describe the earlier stages of development). It has been claimed that girls make up a higher proportion of subjects in adolescence (Gittleman and Mannuzza, 1985).

Typically ADDH-children have short attention spans, are distractible and perform poorly on vigilance tasks (e.g. continuous performance task, CPT, Sykes et al., 1973; Thorley, 1984). High levels of behavioral activity are seen in both unstructured playrooms and structured classrooms (review, Solanto, 1984). A certain amount of uncoordinated or clumsy behavior may also be present (Wender, 1971). ADDH-children have been followed up as adults where a residual syndrome consisting more of attentional than hyperkinetic symptoms may remain (Caresia et al., 1984; Weiss, 1985; Wender et al., 1985a). It has only recently been emphasized that symptoms of hyperactivity may not always disappear with age (Safer and Krager, 1985).

I shall now consider the functional and neurobiological concomitants of this syndrome as it is reflected in ADDH-subjects, some related conditions and potentially similar animal models, with particular emphasis on the catecholaminergic (CA) components.

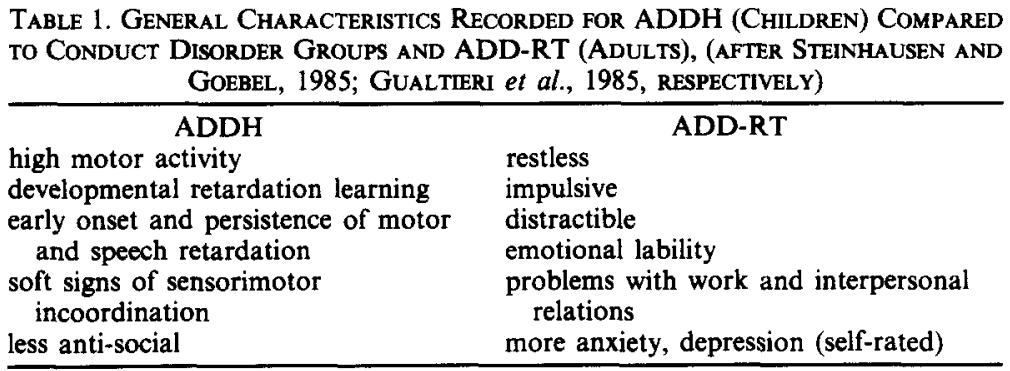




\section{Psychostimulant Treatment-Neurochemical Response}

\subsection{The Psychostimulants}

Bradley (1937) originally observed some 50 years ago that psychostimulant drugs such as amphetamine could have a calming effect on ADDH-children. For the psychomotor stimulants, amphetamine and methylphenidate (but not caffeine, Elkins et al., 1981) the beneficial results of treatment have been reported many times (reviews, Solanto, 1984; Wender, 1971; e.g. amphetamine, $0.1-0.6 \mathrm{mg} / \mathrm{kg}$; methylphenidate, $0.25-2.0 \mathrm{mg} / \mathrm{kg}$ ).

The effect of the indirect dopamine (DA) agonist amphetamine is often described as paradoxical. But, in hindsight one may say there was good reason to have tried it out. "Post-encephalitic" subjects, who had often shown some Parkinsonian-like symptoms, were later found on post-mortem examination to show degeneration in the substantia nigra. Later this area was recognized to contain the A9 DA neurons.

At low to moderate doses amphetamine and methylphenidate promote CA utilization in the synapse by facilitation of synthesis and release, by the blocking of CA reuptake and inhibition of the catabolic enzyme monoamine oxidase (MAO). Of these effects methylphenidate preferentially blocks reuptake but amphetamine affects other mechanisms more potently (Axelrod, 1970; Szporny and Garog, 1961). Amphetamine facilitates release from reserpine-resistant neuronal pools of CA but methylphenidate may be more effective on vesicular pools of CA in certain brain structures (reviews, Langer and Arbiller, 1984; Solanto, 1984). Studies of the binding of the tritiated ligands in neostriatal preparations found that amphetamine sites tended to be post-synaptic and threo-methylphenidate sites pre-synaptic (Hulihan-Giblin et al., 1985). Amphetamine inhibits electrically-induced DA release but facilitates electrically-induced NA release (Langer and Arbilla, 1984).

Widely used names for stimulatory agents in use are Dexedrine (amphetamine), Ritalin (methylphenidate), Cylert (pemoline), and Eutonyl for the MAO inhibitor pargyline. Commonly experienced side-effects of the conventional stimulants are anorexia, insomnia, weight loss and stomach pains (Golinko, 1982).

\subsection{The NeUROchemical Response}

The response of neurotransmitter metabolism to pharmacological treatment of ADDHchildren has been sought in the metabolite levels of various body fluids. Ethical considerations usually preclude more invasive techniques to investigate the CSF or neural sites. Thus the neurochemical data of the following discussion must be regarded as only an indirect reflection of central nervous changes, being, as they are in the main, measures from the plasma or urine. It has been reported that $20-60 \%$ of urinary MHPG (NA metabolite) reflects central CA metabolism. It is unfortunate that the precise contribution of central NA activity to urine or plasma NA levels remains, quantitatively, obscure. Nonetheless in normal mammals there is a growing body of evidence of an interactive link between central and sympathetic NA activity (e.g. Maas, 1984). It has been argued that $33 \%$ (urine) to $45 \%$ (plasma) of HVA, a DA metabolite, reflect central DA metabolism (e.g. Kopin, 1978). Urinary HVA is derived from plasma with no contribution from renal DA metabolism (Elchisak et al., 1978), (cf also Maas et al., 1979; Kopin, 1978; Kopin et al., 1984; Swann et al., 1980 and discussion in Commissiong, 1985; Sternberg et al., 1983).

With regard to the contribution of serotonin $(5-\mathrm{HT})$ of central origin to levels in the plasma or urine the situation is far more problematic. There is a disproportionate amount of 5-HT in the periphery with the CNS containing $1-2 \%$ of endogenous levels of 5-HT (review, Raskin et al., 1984).

\subsubsection{Catecholamines $(C A)$}

Up to ten years ago there was no indication of changed CA metabolic rates in ADDH-subjects judged by the levels of urinary metabolites (Solanto, 1984). In 1976 


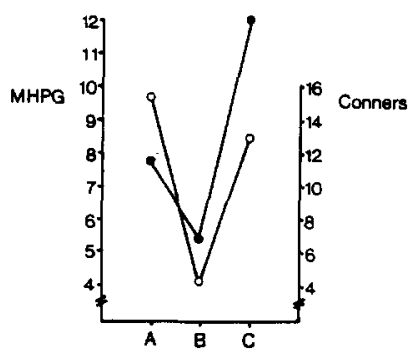

FIG. 1. Mean urinary MHPG excretion ( $\times 100 \mu \mathrm{g} / 24 \mathrm{hr}$ ) (O) and mean Conners clinical rating score $(O)$ of distractibility, attention span, impulsivity and hyperactivity for 73 hyperactive children (DSM III): (A) before, (B) after 3 weeks treatment with methylphenidate $(0.3 \mathrm{mg} / \mathrm{kg} / \mathrm{day})$ and (C) 3 weeks after end of treatment. Mean MHPG levels for male and female controls were 1029 and $848 \mu \mathrm{g}$ respectively. Diagnosis did not exclude those with a history of brain damage ( $n$ 35), but this group showed no significant differences of metabolite levels, (adapted from Shen and Wang, 1984).

Wender suggested subdividing ADDH-subjects on the basis of decreased DA or NA metabolism. Since then many correlations have been reported. This apparent success is probably due in part to more careful measurement. Thus the variable body areas of young subjects were taken into consideration and more than one sample would be taken precluding the variability of metabolite excretion at different times of day. The bad news is that the correlations found do not always agree between studies.

The results of recent studies are complex, but suggest the following pattern in which the presence of a positive therapeutic response is crucial. First I describe the results from several laboratories, which form a consensus, even though not all the studies were strictly controlled. There follow two dissenting results of controlled studies, which are themselves not beyond criticism.

ADDH-children may excrete normal or low levels of MHPG. Irrespective of the level of MHPG, those subjects responding to amphetamine showed a drop of MHPG levels (Hunt, 1982; Shekim et al., 1979). A recent open study with an unusually large number of subjects (73 with ADDH-related diagnosis vs 57 controls, Shen and Wang, 1984) found that hyperactive children showed 20\% lower urinary levels of MHPG and those that responded to methylphenidate showed a further $20 \%$ decrease (with large standard deviations). Unusually this Chinese study included girls ( $n 11)$ who showed a trend toward lower MHPG levels than boys in both groups. Together such results suggest that changes of NA metabolites alone cannot account exclusively for symptoms and symptom changes, despite the reported correlation between the neurochemical response and clinical improvement (Fig. 1).

In subjects that responded to treatment, HVA levels are the mirror image of MHPG levels (i.e. normal MHPG, low HVA: low MHPG, normal HVA: cf Table 2). Shekim and coworkers $(1982,1983)$ found that, in subjects responding to amphetamine, normal HVA levels decreased and low HVA levels increased. This result gives the impression of a drug-induced homeostatic effect. But, surprisingly, the reference HVA/MHPG relationship

Table 2. Levels of CA Metabolites as Percentage of Control Levels after AMPHETAMINe TREATMENT ( 2 WEeks, $0.5 \mathrm{mg} / \mathrm{kg}$, TWICE DAILY) OF HYPERACTIVE Children (Clinical Criteria for Hyperkinesis) and the CA Metabolite RATIO BEFORE AND AFTER TREATMENT (ADAPTED FROM SHEKIM et al., 1982)

\begin{tabular}{lcccc}
\hline & MHPG & HVA & HVA/MHPG ratio \\
& $108 \%$ & $106 \%$ & 5.1 & 4.9 \\
\hline $\begin{array}{l}\text { Non-responders } \\
(n, 6)\end{array}$ & $57 \%$ & $150 \%$ & 2.5 & 5.5 \\
$\begin{array}{l}\text { Responders (normal MHPG) } \\
(n, 9)\end{array}$ & $76 \%$ & $82 \%$ & 5.5 & 6.0 \\
$\begin{array}{l}\text { Responders (low MHPG) } \\
(n, 6)\end{array}$ & $929 \mu \mathrm{g} / \mathrm{m}^{2}$ & $3068 \mu \mathrm{g} / \mathrm{m}^{2}$ & \multicolumn{2}{c}{3.3} \\
$\begin{array}{l}\text { Controls } \\
(n, 12)\end{array}$ & & & & \\
\hline
\end{tabular}


achieved with treatment seemed to be closer to that of non-responders than that of healthy untreated controls (Table 2). Shetty and Chase (1976) also found that treatment reduced levels of HVA. This reduction correlated highly with clinical improvement (0.96) recalling the similar correlation with MHPG levels reported in the Chinese study (Shen and Wang, 1984). These results are supported by one of CSF HVA levels, where, after probenecid treatment the level of HVA was found to be reduced (Shaywitz et al., 1977).

Wender's laboratory reported that in ADDH-subjects of the residual type (ADD-RT) methylphenidate reduced CSF-HVA in responders but increased it in non-responders to drug treatment (Reimherr et al., 1984; Wender et al., 1984).

Thusfar the conclusion is that amongst responders to psychostimulant therapy (in admittedly sometimes rather broadly diagnosed ADDH groups) there are those with low NA metabolism and a second group with low DA metabolism. Curiously in both groups improvement is associated with a further lowering of metabolite levels which suggests that the CA metabolic anomaly is contingent on a third, as yet unknown, factor. Further there is a third group of subjects consisting of non-responders to psychostimulants.

Two recent studies, one with adults (ADD-RT, Mattes et al., 1984) and one with children (ADDH, Zametkin et al., 1985), appear at first sight to confuse this consensus.

In the first study Mattes reported a low success rate after methylphenidate treatment (ADD-RT; 16/61 responders). They could find no correspondence between therapeutic response and childhood history, personality disorder and depression. But as a number of responders were known for their abuse of drugs, they suspected that a history of "self-medication" may have been helpful in these cases. Perhaps with decreasing plasticity of the nervous system in late adolescence, psychostimulant therapy is less efficacious and useful only if persistently administered. Pre-exposure to psychostimulants is well known to be able to sensitize future responses to either stimulants themselves or stressful stimuli (Angrist et al., 1980; Antelman et al., 1980; MacLennan and Maier, 1983).

In the study of children, Zametkin and colleagues report on a mixed group of subjects that included children with conduct disorder, after treatment with methylphenidate $(n 10)$ or amphetamine ( $n$ 12). In the former group all measures of NA and DA metabolism increased and in the latter they decreased. However as DA measures were more variable the changes did not prove to be significant (although they were of the same magnitude as those for NA). For supporters of the NA hypothesis the only problem was that there was no correlation between neurochemical and clinical response. It is unfortunate that a specific test of attention was not administered. However the data are not quite as paradoxical as they seem. If the data are viewed in terms of utilization (metabolite:CA) both drugs tended to suppress NA and DA utilization (above) (e.g. HVA/DA $=13 \%$, MHPG/NA $=19 \%$ for methylphenidate). Broadly, amphetamine showed less of an effect on NA than on DA utilization. But the more individually variable DA response, which may well reflect separate sites for the action of these drugs, was less closely investigated.

It is perhaps important to remember that acute treatments of animals' mesolimbic and mesostriatal areas with psychostimulants is reported to produce changes in the opposite direction from the above report on ADDH children (e.g. Nielsen et al., 1983). Chronic treatment exacerbates the acute effect of amphetamine treatment (Kokkinidis and Anisman, 1980; Segal et al., 1980). In the above ADDH study it is less important whether utilization decreased than that it did not increase, as might have been expected. It may be that part of the problem is a neurochemical analog to rate dependency of behavioral response (see below) (i.e. low and normal metabolic levels are stimulated, high anomalous levels are inhibited). Relevant here is a recent study (Archer et al., 1985) showing decreased rat motor activity in response to amphetamine treatment following depletion of NA. The effects of psychostimulants depend in a complex way on dose and regional CA levels. Here much work still remains to be done in animals.

\subsubsection{Serotonin $(5-H T)$}

Is it wise to ignore a possible dysfunction in ADDH subjects of the closely related monoamine neurotransmitter 5-HT? As has often been pointed out, just as treating the 
symptoms of rheumatic fever with aspirin informs little about the cause, so might the treatment of ADDH subjects with psychostimulants be uninformative and misleading with regard to the CA contribution.

But the indications do not favour a role for anomalous 5-HT metabolism in ADDH. Despite early reports of decreased platelet 5-HT (Bhagavan et al., 1975) and blood 5-HIAA (metabolite) (Coleman, 1971), these results have not been replicated (Rapoport et al., 1974; Ferguson et al., 1981). Further, no differences in the levels of the metabolite have been found either in urine of ADDH children (Wender et al., 1971) or in the CSF with (Shetty and Chase, 1976) or without probenecid pretreatment (Shaywitz et al., 1977).

\subsection{Electrophysiological Indices of COGNition}

What is the nature of the attentional and motor improvement that "responders" to psychostimulants show? It is unfortunate that for the interpretation of the results of cognitive performance, such studies have not yet been published where the effects on CA metabolism were also documented.

An early report provided initial evidence of a latent excitability of the nervous system of hyperkinetic children (broad selection criteria: Laufer et al., 1957). The threshold for the induction of a myoclonic jerk by stroboscopic stimulation during metrazol infusion was determined. The rather low threshold obtained in this group was increased under amphetamine treatment. At the least this result is compatible with the electrophysiological inhibition of DA neurons observed after the treatment of animals with amphetamine. But the implications do not seem to have been followed up in ADDH groups.

A number of early EEG studies of ADDH-children reported the presence of excessive amounts of slow wave activity, but that such "dysrhythmias" disappeared as the subjects grew up (Burks, 1964; Capute et al., 1968; Hechtman et al., 1978). More recently Caresia et al. (1984) reported on adult subjects. Non-responders, like ADDH-children, showed increased activity in the $6-8 \mathrm{~Hz}$ band and decreased activity at $10-13 \mathrm{~Hz}$. In contrast, responders showed a decrease for the $6-10 \mathrm{~Hz}$ and an increase for the $10-13 \mathrm{~Hz}$ bands. These changes are consistent with the increased ability of the responders to concentrate.

Unexpectedly, Caresia and colleagues could find no significant effects in their sample of ADDH-children where eight out of nine responded to pemoline. However, their data did at least show a trend for these subjects towards higher beta activity. Such an effect is also seen in healthy subjects (Finch, 1968). (Of course reports of apparently conflicting results for relatively small samples are not unexpected where records from normal subjects vary considerably with emotional state, between individuals and depend on the state of maturation.)

Records of auditory evoked potentials from the brain stem of ADDH children have not shown a consistent impairment in the registration of sensory stimuli (Gualtieri et al., 1985). But studies of event-related potentials (ERPs) show that the psychostimulants can affect both the cognitive and motor symptoms of ADDH-subjects, although it seems that methylphenidate may primarily improve response selection rather than stimulus evaluation. (Recent evidence suggests that auditory P3b and slow wave amplitudes, possibly reflecting the perceived significance of stimuli, are often smaller in ADDH-children (Holcomb et al., 1986).)

A Californian laboratory has reported on the effects of three doses of methylphenidate on ADDH-children (7-13 years: Elliott et al., 1978; Halliday et al., 1979; 1983). Visual ERPs were elicited by flashes of light of varying brightness in situations that did or did not require a response (active and passive attention). This group found, with increasing dose, a decreasing negativity of the anticipatory $\mathrm{N} 2$ complex in older, but an increasing positivity in the younger children (10 year). They also reported a small but opposite effect of the stimulant on attention-related processes as a function of either increasing age or course of the condition. But surprisingly they could find no difference of latency for the N2 and P3 complex despite subjects showing improved reaction times after treatment.

More recently this laboratory has confirmed that N1 latency did not differ between ADDH- and normal children and there was no differential effect after methylphenidate 
treatment (Callaway and Halliday, 1982). (But it should be remembered that where reaction times improve with maturity by ca. $1 \mathrm{msec}$, so ERP latencies normally decrease by $0.5 \mathrm{msec}$.) Thus these results seem to show that there was a response related effect of the drug (reaction time) separate from that on attention-related processes (N1/P3 complex) in their ADDH subjects. This result was recently confirmed for the P300 wave (Naylor et al., 1985). However it is appropriate to remark here that it is a common finding, in a situation where latencies decrease, that reaction times shorten far more (Johnson et al., 1985). Thus in view of the complexity of the stimulus and maturation variables involved, a negative result for an effect of psychostimulants requires further replication.

\subsection{BeHavioral INDices of COGNITION}

Psychostimulants have been consistently found to improve social behavior, activity and learning in a little over half of ADDH-children (e.g. Bradley, 1937; Burks, 1964; Hechtman, 1985) and adolescents or adults with residual signs (Varley, 1985; Wender $e$ t al., 1985b) despite the absence of convincing support from electrophysiological studies of the potential mechanisms (above). Indeed some authors prefer to emphasize that despite reports of improvements on tests of attention following treatment, educational advance does not necessarily follow and serious personality problems can develop (e.g. Gualtieri et al., 1985). What are the characteristics of the poor learning performance attributed to ADDH-children that have been reported to be improved by psychostimulants?

On choice tasks with warning signals that do not require much attentional effort, ADDH-subjects are reported not to show much impairment. But they are more impaired on serial or self-paced reaction time tasks. On the CPT that requires the selection of a rare target during a long presentation of stimuli, they make both more errors of omission (a problem of concentration) and more redundant responses (motor control or stimulus evaluation problem). Stimulants increase the number of correct responses (Goldberg and Konstantareas, 1981; Klorman et al., 1979; Kupietz, 1976; Sykes et al., 1971, 1972, 1973).

The administration of stimulants to normal children reduces the number of CPT errors of omission. Thus it has been claimed by one laboratory that from a therapeutic and research viewpoint the decrease of errors of commission is more significant (Rapoport et al., 1978, 1980; Zahn et al., 1980). However this is far from established. One of the tasks most frequently administered to ADDH-subjects is the matching of familiar figures (MFFT) test of cognitive style (Glow et al., 1983). Methylphenidate clearly improves the performance of ADDH-subjects on this task (Ballinger et al., 1984). A study relating CPT and MFFT performance showed that both types of CPT error correlate with MFFT latency to first response (negatively) and total MFFT errors (positively); only with the overall MFFT latency measure was there a difference (Table 3; Klee and Garfinkel, 1983)

Table 3. (A) Correlations between Continuous Performance Task (CPT) and Other PSYCHOMETRIC VARIABLES FOR CHILDREN WITH ADDH, CONDUCT aND AFFECTIVE Disorders (DSM III, $n, 51$ ). Conners Teacher Rating Scale (CTRS), Match Familiar Figures Test (MFFT), Wechsler INTELLIGENCE SCALE FOR ChILDREN-ReVised (WISC-R)

\begin{tabular}{|c|c|c|c|c|c|c|c|}
\hline & \multicolumn{6}{|c|}{ Partial order controlling for age } & \multirow[b]{2}{*}{ age } \\
\hline & CTRS & $\begin{array}{c}\text { MFFT } \\
\text { Ist }\end{array}$ & $\begin{array}{c}\text { MFFT } \\
\text { total }\end{array}$ & $\begin{array}{l}\text { MFFT } \\
\text { errors }\end{array}$ & $\begin{array}{l}\text { WISCR } \\
\text { coding }\end{array}$ & $\begin{array}{c}\text { WISCR } \\
\text { arithmetic }\end{array}$ & \\
\hline $\begin{array}{l}\text { Omission errors } \\
\text { Commision errors } \\
\text { CPT total errors }\end{array}$ & $\begin{array}{l}0.32^{*} \\
0.36^{2} \\
0.38^{2} \\
\end{array}$ & $\begin{array}{l}-0.28^{*} \\
-0.35^{2} \\
-0.36^{2}\end{array}$ & $\begin{array}{l}-0.09 \\
-0.33^{*} \\
-0.26\end{array}$ & $\begin{array}{l}0.31^{*} \\
0.34^{*} \\
0.28^{*}\end{array}$ & $\begin{array}{l}-0.32^{\star} \\
-0.25 \\
-0.31^{*}\end{array}$ & $\begin{array}{c}-0.37+ \\
-0.12 \\
0.05\end{array}$ & $\begin{array}{l}-0.52 \dagger \\
-0.49 \dagger \\
-0.56 \dagger\end{array}$ \\
\hline
\end{tabular}

(B) Partial Correlations Between CPT and CTRS Factor Scores

\begin{tabular}{lccccc}
\hline \multicolumn{1}{c}{ Factors } & Conduct & Inattention & Anxiety & Hyperactivity & Sociability \\
\hline Omission errors & -0.05 & 0.31 & -0.10 & $0.36 \dagger$ & 0.21 \\
Commission Errors & -0.03 & 0.33 & -0.01 & $0.34^{*}$ & 0.05 \\
CPT total errors & -0.04 & $0.33^{*}$ & -0.04 & $0.35 \dagger$ & 0.12 \\
\hline
\end{tabular}

$* p<0.05$.

$+p<0.01$.

After Klee and Garfinkel, 1983. 
(this study reported on a mixed group of hyperkinetic children). Indeed in support of the contention that MFFT results after treatment reflected measures of cognitive style rather than mere impulsivity (Glow et al., 1983) signal detection measures have also shown that methylphenidate will improve target detection and target discrimination ratios of normal adults on dichotic listening tasks (Clark et al., 1984).

There are two points here. The first is that psychostimulants may improve poor performance on a task of attention and learning but not that ADDH-subjects necessarily have a peculiar or specific deficit. For example, a recent study of 400 college students reported that the poor CPT performance of the bottom $5 \%$ correlated both with ADDH-related features in their history and other attentional measures (e.g. ERP and Stroop test: Buchsbaum et al., 1985). This suggests that there is a quantitative rather than a qualitative difference in the symptoms under study.

The second point is that, taken with the electrophysiological data of the previous section, these results emphasize that there are two significant factors in ADDH and that stimulant treatment can (but may not) improve both. They may be termed response control (cf reaction time latencies) and the control of vigilance, an attention-related factor (cf CPT/MFFT errors, Table 3).

This distinction between response and attention/vigilance factors in ADDH may seem elementary for it is reflected in terms of the rating scales in clinical practice (Conners and Wells, 1979; Conners teacher scale, Table 3). But it is an important point to be made in some quarters and is capable of being developed into a valuable distinction for the future establishment of diagnosis and for research into the underlying factors.

Other types of experimental study also point to this distinction and that treatment with psychostimulants improves both information processing and response organization. Such studies have measured performance on Porteus mazes (sensitive to cognitive strategies) and stylus mazes (sensitive to fine motor control) (Conners, 1972; Conners et al., 1969; Epstein et al., 1968; Knights and Hinton, 1969). Indeed to emphasize the distinction between these two factors one may remark that the ADDH-subjects who show improved learning after stimulant treatment are not necessarily those who show less of a motor impairment (Weingartner et al., 1982). Where subjects show both improvements, the cognitive effect may deteriorate long before the calming effect of treatment wears off (Solanto and Conners, 1982).

A last piece of evidence for the distinction between these two factors comes from clinical experience. It has been reported that optimal cognitive effects are produced by a lower dose of methylphenidate (ca $0.3 \mathrm{mg} \mathrm{kg}^{-1}$ ) whereas higher doses (ca $1.0 \mathrm{mg} \mathrm{kg}^{-1}$ ) are needed to produce favorable changes of social behavior (Sprague and Sleator, 1977). (There is an inverse U-curve relationship for the improvement of learning with dose, but a linear relationship for the improvement of classroom activity with dose). The sum of these observations support the idea of two groups of symptoms with variable sensitivity to psychostimulant therapy.

\subsection{Responses to Other MONOAMINERgic Agents}

In view of the evident changes after psychostimulant treatment of psychomotor performance on the one hand and CA metabolism on the other, it makes sense to investigate the therapeutic potential of other CA active agents in ADDH. But so far the potential of such agents has been assessed more according to clinical rating scales rather than on specific experimental test performance.

With "stimulant" as the key word in the success of pharmacotherapy, albeit that the improvement is of a short-lived nature and restricted to a proportion of subjects, it has been natural to follow two experimental strategies. The one is treatment with a transmitter precursor, the other is the blocking of MAO in order to prolong the synaptic life of the transmitter. 


\subsubsection{Precursors ( $L-D O P A$ and amino acids)}

The first strategy has not been successful. In children, CA precursors (e.g. L-DOPA) exert a rather nonspecific sedative effect (Gross, 1977; Jackson and Pelton, 1978). In a controlled study, a rather mild alleviation of symptoms was found which at best permitted a reduction of the level of Ritalin administered (Langer et al., 1982). In residual type subjects a clear but temporary alleviation has been registered. But this was soon followed by a refractory period (Wender et al., 1984; Wood et al., 1982).

The administration of tyrosine, the amino acid essential for the biosynthesis of CAs, would be less beset by the untoward effects of L-DOPA. From animal studies it is encouraging to know that there is a dose-dependent relationship between levels of tyrosine and the amount of electrically-induced DA released from the neostriatum (Milner and Wurtman, 1985). Wood et al. (1985) report on an open study ( $n 12$ adults) where $l$-tyrosine improved target symptoms with a delayed onset similar to that seen after treatment of depression with tricyclic drugs (ca. 21 days). But improvements had disappeared within 6 to 10 weeks. An absence of a lasting therapeutic effect has also been found by Nemzer and Arnold (cit. McConnell, 1985). The report by Wood and his colleagues included a double blind crossover trial of $d l$-phenylalanine (the $l$-isomer can be hydroxylated to tyrosine). The effect was milder. Mood proved less labile. There was a rapid onset and again a disappearance of the therapeutic effect. This, along with the apparent ineffectiveness of the natural $l$-isomer, led the authors to suggest a nonprecursor mode of action for the racemate. At best, amino-acids might be construed as helpful adjuncts to the use of other agents, having less side effects than, for example, neuroleptics.

\subsubsection{Monoamine oxidase ( $M A O)$}

For the second strategy two enzymes may be targeted, MAO A (with NA as substrate) and MAO B (with DA and phenylethylamine as substrate) (Houslay et al., 1976). Concentrating on the DA aspect, Wender and his colleagues (1985a, b) conducted open trials with pargyline (ca. $20 \mathrm{mg} /$ day) and deprenyl (ca. $30 \mathrm{mg} /$ day). Improvement was recorded in 11 out of 16 and 6 out of 9 subjects respectively. (A lower dose of deprenyl has proved less efficacious (Donnelly cit Rapoport et al., 1985). In Wender's adult subjects activity was reduced and attention span improved (Wender et al., 1983). Unfortunately because of the dangers from numerous side effects (especially hypotension and the 'cheese' effect) these agents are unlikely to find wide application. Nonetheless a DA component would seem to be indicated in the symptoms of some subjects.

Rapoport and her colleagues (1985) investigated the combined effects of clorgyline (MAO A action) and tranylcypromine (mixed MAO A \& B action) in a double blind trial. In contrast to the antidepressive effects of the drugs and the relatively slow appearance of the therapeutic effects reported by Wender, an improvement with rapid onset was found. But this was restricted to the factor of "impulsive hyperactivity" as indicated by the Subject Treatment Emergency Symptoms Scale.

A larger scale study with the NA uptake inhibitor DMI showed there was an improvement on the Conners teacher rating scale but not on the CPT (Rapoport et al., 1985; cf also Waizer et al., 1974; Winsberg et al., 1972). Unlike the authors I find this result to be disappointing. Firstly the indication for an NA component in ADDH is indirect. There were no measures of metabolism reported and they merely claim that clorgyline alone was also effective. Secondly an improvement was restricted to one aspect of the syndrome. Further, because of the potential for drug-abuse, therapy with these agents is contraindicated. Another study of the usefulness of imipramine $\left(3-7 \mathrm{mg} \mathrm{kg}^{-1} \mathrm{day}^{-1}\right)$ to block reuptake found it did not help non-responders to methylphenidate (Conners teacher/parent rating scales, Winsberg et al., 1980). Indeed these authors had more success with this group when they used the neuroleptic thioridazine. 


\subsubsection{Alternative directions}

Other ideas for pharmacotherapy have been tried out with little (e.g. neuroleptics see above) or no success (e.g. Lithium, Phenobarbital (Wender, 1971), Fenfluramine (Donnelly cit Rapoport et al., 1985) and Evening Primrose oil (Gibson personal communication)). Nonetheless there are individuals who may respond to such drugs. Thus, for example, Cole (1978) has reported some positive responses from adult subjects treated with lithium or with benzodiazepines. But such results are probably restricted to those individuals with additional problems with behavior, personality or affect. In general, these studies indicate that factors ranging from sedation and affect, to the availability of serotonin and the prostaglandins are not strongly indicated in ADDH.

There is perhaps one further idea that perhaps has potential for development. Taking into account the joint effects of stimulants on NA and DA metabolism, the antihypertensive effects of pargyline and the usefulness of the hypertensive rat as a model for the ADDH syndrome (see below), it would be of interest at least at the research level to study the usefulness of "atypical" CA agonists. One example is the ergoline bromocriptine. This agent is a mixed DA agonist/antagonist with a certain affinity for D2 receptors and, at least after acute administration to animals, it depresses levels of NA and reduces systolic and diastolic blood pressure (Mannelli et al., 1984). Administration of another ergoline, pergolide, produces a drop in tension, which is blocked by the D2 antagonist sulpiride but not by the NA anatagonist yohimbine (Barrett and Lokhandwala, 1983). Other ergolines with alpha antagonist and $\mathrm{D} 2$ agonist properties that reduced blood pressure are also being developed (e.g. Morales-Olivas et al., 1984). Starting with the model of vasomotor action, the development of such agents may yet produce a balance between the unwanted systemic and the desirable neuropharmacological effects in ADDH.

\section{Similarities and Differences with Other Disorders of Catecholamines and Attentional Function}

It is of interest to compare briefly the disorders of three other syndromes to show where there are similarities between clinical symptoms and CA dysfunction, but more importantly to stress that there are limits to speculation about the potential correlations.

\subsection{Phenylketonuria}

There is widespread agreement that patients suffering from phenylketonuria show an increased turnover of phenylethylamine (PEA, an unusual metabolite of NA with a structure similar to amphetamine). Indeed PEA contributes to the symptoms of hyperactivity, excitability, lability of mood and short attention span shown by those with phenylketonuria (Wolf and Mosnaim, 1983).

On the one hand it may be no surprise that subjects with phenylketonuria show a broad range of symptoms when there is such a widespread pathological deposition of phenylalanine. On the other hand it is striking that these particular symptoms should be apparent.

Is a putative PEA-attention dysfunction link relevant for ADDH subjects? Recently Zametkin et al. (1985) reported that a $1600 \%$ increase in the excretion of PEA was found after treating ADDH-children with amphetamine (but not methylphenidate). The first implication is clearly that one should look for PEA excretion in further studies of ADDH subjects and particularly one should look to see if it is enhanced by treatment with the structurally similar amphetamine. Secondly, abnormal CA metabolism is implicated. Thus as MAO inhibitors should promote the elimination of this amine, there is good reason to explore this therapeutic strategy further (cf PEA is a substrate for MAO B). The opposite might be said about the wisdom of increasing the activity of DA or treatment with DA precursors that could lead to an increase of PEA if this abnormal metabolic pathway is more usual in ADDH subjects.

It is particularly interesting that investigations of the potential contribution of PEA to the above named symptoms of phenylketonuria and to thought disturbance in schizo- 
phrenia have shown a tendency for it to be accumulated in neostriatal and limbic structures. These are two subcortical areas that are particularly important for the evaluation of sensory information and its use in organizing adaptive behavioral strategies (review, Oades, 1982a; Oades et al., 1985a; Wolf and Mosnaim, 1983). Clearly CA metabolism and function in these brain regions merits particular attention.

\subsection{TOURETTE's SYNDROME}

A second disorder, Tourette's syndrome may be mentioned in the present context. Recalling the way ADDH was first perceived, Tourette-like symptoms quite often follow encephalitic infections (review, Messiha and Carlson, 1983). Suggestions for biological dysfunction in Tourette's syndrome remain controversial, but include DA hyperfunction in the neostriatum (cf oral stereotypies, Stahl and Berger, 1982). An increased cortical excitability has also been proposed on the basis of evoked potentials recorded from the scalp. However it should be noted that such potentials can reflect activity in the septohippocampal region from which abnormal excitability has been recorded in attention disordered schizophrenics (Heath, 1966).

Amongst the various symptoms of Tourette's syndrome, clinicians often encounter hyperactivity associated with a decreased attention span. The more dominant symptoms of motor (and phonic) tics, associated with dysfunction of the basal ganglia, are alleviated by haloperidol treatment. However such treatment exacerbates the ability to process temporal information (Goldstone and Lhamon, 1976) and generally blunts cognitive ability (Werry and Aman, 1975). From this it would seem as if excessive mesostriatal DA activity had been normalised but normal mesolimbic DA activity attenuated. In contrast clonidine, an inhibitory alpha NA agonist, although less efficacious in general, does produce less cognitive blunting (Shapiro and Shapiro, 1982). Although the mechanism of action of clonidine is poorly understood, the results do imply that a judicious manipulation of the interplay between cortical NA and DA could assist attentional function. At the least, as there are parallel DA projections to the neostriatal and septal regions a closer comparison of symptoms between this syndrome and ADDH could be helpful for subjects with impaired DA metabolism.

\subsection{LESCH-NYHAN SYNDROME}

Finally in order to show that there are severe limits to speculative proposals for explaining the CA bases of ADDH, it is worth discussing briefly the Lesch-Nyhan syndrome (Lesch and Nyhan, 1964). Seegmiller and coworkers (1967) demonstrated that a specific inborn deficiency of purine metabolism is responsible for the syndrome. But reduced DA function in several brain regions has been reported from Lesch-Nyhan subjects post-mortem (Lloyd et al., 1981). CSF measures taken at intervals during development of four subjects showed consistently lower levels of HVA (Silverstein et al., 1985).

The biochemical results are partly consistent with what is known about the neurobiological bases of the main symptoms of hypertonicity, choreoathetoid movement, self mutilation behavior and mental retardation (Baumesister and Frye, 1985; Kelley and Wyngaarden, 1983). Indeed Breese and his colleagues (1984) have now modelled this symptom picture remarkably closely in the rat by depleting DA levels neonatally and additionally stimulating the hypersensitive system with $D A$ agonists later in development.

On the surface it seems that the syndrome and the model demonstrate comparable behavior but opposite changes of DA metabolism. However the lesson here is that one does not know precisely what happened to the DA system (e.g. local utilization and binding changes). Indeed in either case it seems that an increase or a decrease of DA function, by different criteria, can give rise to a symptom picture quite different to ADDH. This should be surprising if one wishes to maintain that apparently similar biochemical changes in ADDH and a putative animal model (cf below) result in comparable changes 
of cognitive and motor performance. The matter would perhaps be resolved by a clarification of both the descriptor "mental retardation" in the case of the clinical condition and quantification of the parameters of DA change in the animal model. Nonetheless the warning that arises out of the present results is pertinent both to postulates of what the changes are that underlie ADDH as well as to the direction that proposed pharmacotherapeutic strategies should take.

\section{Parallels to Experimental Animal Studies}

\subsection{Attention-Related Symptoms}

On search-learning tasks many ADDH children readily understand the requirements and indeed get as far as achieving reinforcement, but they may take very many trials to actually reach criterion (Dykman et al., 1979, 1980). Such subjects were also reported to show many inter-trial responses. A recent review of animal studies (Oades, 1985) described how the similar problem of achieving a respectable learning criterion on a number of different tasks has been reported after damage to the dorsal NA bundle. NA-depleted animals may quite rapidly attain a $66 \%$ criterion but take a very long time to reach $80-90 \%$ correct performance. Indeed depletion of NA can also lead to distractability and irrelevant responses, so long as the depletion occurs before decisions about the performance have to be made and the task acquired (Oades, 1985). The parallel seems quite striking.

A10 lesions in the midbrain of rats, that can lead to DA receptor supersensitivity in the forebrain (Simon et al., 1980) or even amphetamine administration (Oades et al., 1985b), can induce increases of irrelevant collateral behavior during task performance. These changes have been interpreted as indicating an attentional dysfunction arising from uncontrolled DA activity. This in turn interferes with learning. Also pertinent is the finding that treatment with DA antagonists can impair incentive learning in animals (review, Beninger, 1983). These manipulations change DA activity in different ways. They appear to affect the function of different behavioral mechanisms. But in both cases learning is impaired.

Recalling the difficulties ADDH-subjects are reported to have on Porteus mazes (above) and the use of the search task as a soft sign for frontal damage, it is of interest that disruption of the mesocortical DA projection interferes with the development of tasksolving strategies by rats searching for food on a holeboard or in a maze (Oades, 1981, 1985; Oades et al., 1985a, b; Simon, 1981).

From studies of the performance on paired associate learning tests there is evidence that ADDH-subjects employ a different cognitive style or different strategies for information processing (Weingartner et al., 1980, 1982). These authors have suggested that amphetamine could act by "strengthening" the memory traces produced by the particular dominant processing strategy in the individual subject. However they also noted that the drug-induced improvement could be stronger during the acquisition stage, particularly when effortful attentional processes were required.

Without trying to establish the validity of an attention- vs a memory-related hypothesis, we may note parallels for both types of cognitive style in studies of animal information processing ability. The first suggestion is reminiscent of the facilitation of retrieval of maze performance, learned three weeks previously, in rats after treatments with CA agonists that promoted the release of NA in hippocampal and neocortical areas (e.g. Sara et al., 1984). The second effect parallels some of the effects of lesions of the A10 DA region. For example, lesioned animals can learn a simple visual discrimination but not the more effortful delayed alternation (Simon et al., 1980). Such animals can acquire a preference for the first of four correct food-hole visits on a holeboard with 12 empty holes, but not develop a normal, but more complex, preferred sequence of four food hole visits (Oades, 1982b; Oades et al., 1985a).

Finally Crider and his colleagues (1982) showed that treatments which induce DA receptor supersensitivity in mesolimbic projection areas such as the nucleus accumbens can 


\section{CONDITIONED BLOCKING: RESPONSE LATENCIES}

TO EARLY AND LATE TEST STIMULI

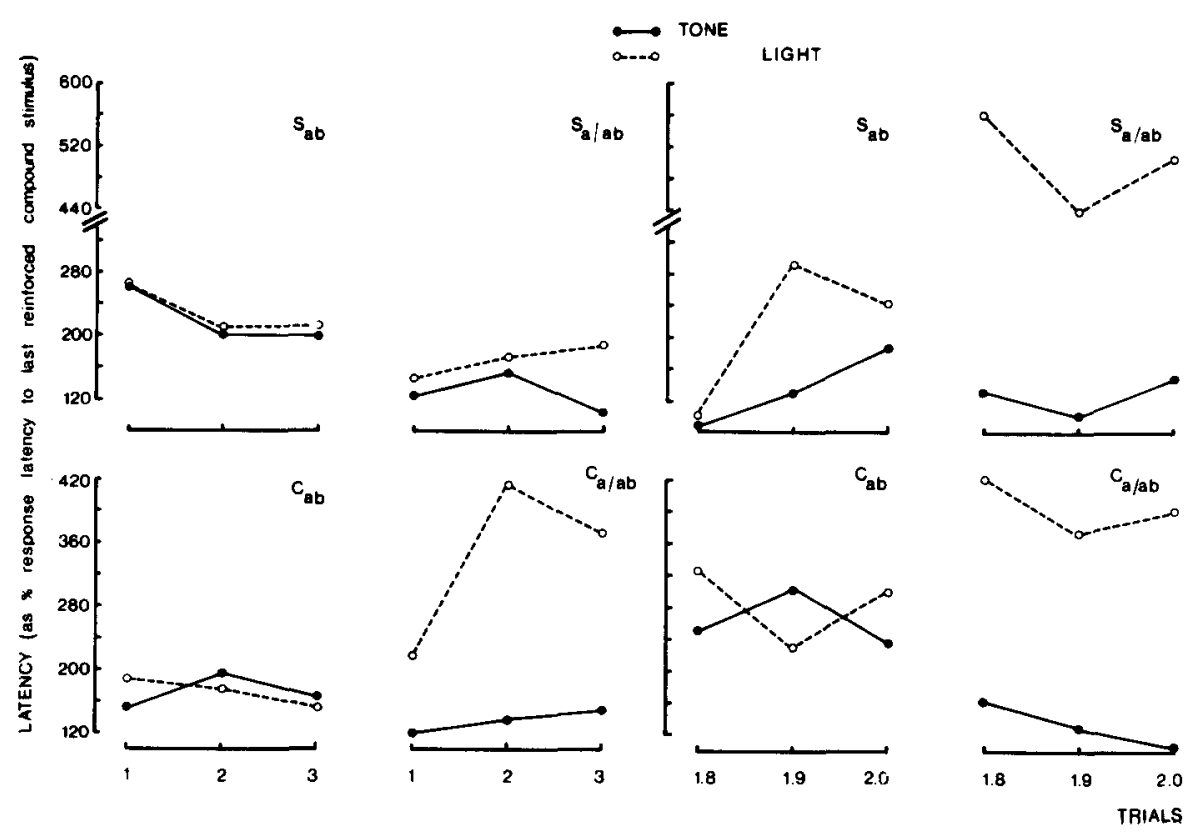

FIG. 2. Escape-response latencies of rats to the first (left) and the last (right) three presentations (20 test trials) of a non-reinforced tone (a: solid line) or light (b: broken line) in a shuttle box after avoidance training with stimuli "ab" or " $a$ " followed by "ab". Latencies are shown as a percentage of that for the last reinforced (footshock) presentation of "ab". (Test sequence: a,b,a,ab,b,a,b,ab ....) S ( $n$ 11); septal lesion with 6-OHDA (DMI protection of NA terminals): C $(n 18)$ injection of vehicle. Attenuation of blocking to " $b$ "( $S_{\mathrm{a} / \mathrm{ab}}$, trial $1-3$, response to " $\mathrm{a}$ " and " $\mathrm{b}$ ") preceded normal or exaggerated blocking ( $S_{\mathrm{a} / \mathrm{ab}}$, trial $18-20$, response only to "a"), $p<0.05$.

result in the animals paying attention to redundant stimuli (e.g. latent inhibition, conditioned blocking). It has also been found that infusing a DA toxin (6-OHDA) into the septum or frontal cortex of rats can impair the performance of a conditioned blocking task (Oades et al., 1985a, 1986; Fig. 2), which is claimed to be a measure of attentional function (Mackintosh, 1975).

These results indicate potential neurobiological bases (i.e. limbic and cortical CA activity) for some of the attention-related changes attributed to the ADDH syndrome.

\subsection{HYPERACTIVITY SYMPTOMS}

It is difficult to resist drawing a comparison between clinically observed hyperactivity and that which follows stimulation of lesion-induced DA supersensitivity in the nucleus accumbens, septum and perhaps frontal cortex of rodents (Carey, 1982; Dunnett et al., 1984). Locomotor hyperactivity can reflect an imbalance between NA and DA activity in these areas (Fishman et al., 1983; Oades et al., 1986a).

However the lesion-induced syndrome should not be taken too literally as a model for the hyperactive ADDH syndrome. Although amphetamine treatment no longer stimulates locomotion in animals with lesions of the ascending A10-DA innervation, an actual reduction of locomotion is not usually recorded (Koob et al., 1981).

Perhaps more relevant for comparison with the $\mathrm{ADDH}$ condition is an interesting genetic model (Helmeste and Seeman, 1982). There are strains of mice with unusually low or high densities of DA receptors. Such mice with high receptor densities, like rats with lesion-induced receptor supersensitivity, may show little abnormal daytime activity yet high levels of locomotion at night (their normal active period). Treatment of these mice 
Table 4. The Habituation of Activity and the Latency for Avoidance in Learning a Shuttle Box Avoidance Task for Rats at about Four WeEks of Age after Neonatal DEPLETION OF NA, DA OR BOTH CAS (AFTER RASKIN et al., 1983)

\begin{tabular}{|c|c|c|c|c|}
\hline & \multicolumn{2}{|c|}{$\begin{array}{c}\text { Time spent active: } \\
(\% \text { total time in activity cage })\end{array}$} & \multicolumn{2}{|c|}{$\begin{array}{l}\text { Avoidance latency (sec): } \\
\text { (Shuttle box) }\end{array}$} \\
\hline & 1st trial & 6th trial & 1st trial & Sth trial \\
\hline Controls & 32 & $24^{*}$ & 14 & $1-2 \ddagger$ \\
\hline NA depleted & 32 & $25^{*}$ & 24 & 148 \\
\hline DA depleted & 31 & $28 \dagger$ & 19 & $14 \S$ \\
\hline CA depleted & 31 & $30^{\dagger}$ & 23 & $23 \|$ \\
\hline
\end{tabular}

* Normal habituation.

$\dagger$ Absence of habituation.

$\ddagger$ Good.

$\S$ Poor.

|| No learning.

with amphetamine induces hypolocomotion. Such strains of mice, where in the Weaver mutation discrete effects on the A10 system may reflect a change in a single gene (Roffler-Tarlov and Graybiel, 1984) provide potentially useful animal models for symptoms of the ADDH condition which itself exhibits a genetic component (cf Shen and Wang, 1984). But it should be noted that the genetic features of the ADDH syndrome may show more similarity to the polygenetic transmission reported for the hypertensive rat discussed below (Louis et al., 1969). It is rewarding therefore to see that increased DA binding has been reported in areas of the basal ganglia of hypertensive rats (Hellstrand and Engel, 1980).

The depletion of CAs in rats after the neonatal, intracisternal application of 6-hydroxydopamine (6-OHDA) has been proposed as an experimental model for ADD with hyperactivity (Raskin et al., 1983; Shaywitz et al., 1976; Smith et al., 1983; but caveat Lesch-Nyhan model above). After such treatment (without pharmacological stimulation) hyperactivity appears in adolescent rats (day 14-23) and disappears in adulthood, in some ways similar to ADDH. The learning deficit of these animals shown on avoidance tasks remained in the adult, like ADD-RT. Raskin et al. (1983) compared the results from animals with specific protection or depletion of NA. The combined behavioral deficit (activity and learning) proved more marked and persistent if both CAs were depleted. Alone NA depletion produced only the learning deficit in adults (Table 4). An advantage of this model is that the activity of both CAs is affected by the manipulation. A disadvantage for experimental analysis is that the lesion technique produces very variable results. In addition it would be useful to have more information on the nature of the learning deficit than that as yet provided by shock avoidance performance.

Finally we may note a possible further reason for not regarding the relative success of amphetamine treatment as paradoxical. Certainly low doses of amphetamine in animals usually increase locomotion. But it is well-known that when baselines of operant responding are high, amphetamine treatment reduces response rates (reviews of rate dependency, Dews and Deweese, 1977; Sanger and Blackman, 1976). Note that in practice, whether increases or decreases of exploratory locomotion are recorded depends both on the basal level of DA activity (Costall et al., 1980) and on the dose of amphetamine (Fishman et al., 1983; Scheel-Kruger, 1971).

A precise test of the explanatory value of the rate dependency hypothesis for ADDH subjects, linking psychostimulant dose, baseline CA activity and behavioral activity in all conditions has not been published. To be sure, there are claims that support the hypothesis. On a mixed fixed ratio/delayed response schedule low baseline responders increased whereas high baseline responders did not increase response rate after methylphenidate treatment (in comparison with placebo treatment: Weber, 1985). -However others have reported inconsistent results (e.g. a variable responsiveness on fixed interval and an unpredicted increased responsiveness on variable ratio schedules: Rapport et al., 1985). A re-analysis of some studies (Robbins and Sahakian, 1979) suggested that perhaps $30 \%$ of the variance recorded could be attributed to rate dependency effects. In the light of what, 
at best, could be considered a minor contributing effect, and what still might prove to be a statistical artifact, it simply does not seem that the rate dependency hypothesis has much explanatory value in the case of the symptoms of ADDH (but cf Green and Warschauer, 1981 vs Millard and Standish, 1982).

\section{An Animal Model-Spontaneous Hypertension}

In contrast to some of the animal studies described above, a good animal model should represent not just one, but a spectrum of the symptoms found in the condition to be modelled. For the ADDH condition two animals have received attention recently-the Telomian-Beagle hybrid and the spontaneously hypertensive rat.

The interest shown by Bareggi and his coworkers (1979) in the hydrid dog is supported by the demonstration in these animals of distractibility, learning impairments and hyperactivity that superficially resemble such characteristics of the ADDH syndrome. Further it is striking that some, but not all of these animals respond favourably to amphetamine treatment by showing improved learning abilities. Such successful treatment is reported to result in decreases of central DA levels and CSF-DA metabolites. However it is not clear if there is an NA component to the anomalous behavior shown by these dogs. This model does not yet seem to have come into widespread use.

\subsection{The Spontaneously Hypertensive Rat (SHR)}

There has been growing interest shown in comparing behavioral and biochemical parameters in normotensive Wistar-Kyoto rats (WKY) with those of the hypertensive Okamoto strain (SHR). (Other SHR strains have also been developed.)

The appeal of the SHR as a model for ADDH lies with their behavioral responsiveness and the underlying neurobiological anomalies. They are hyperactive, hyperreactive but often hypoexploratory (Low et al., 1984). These changes (including hypertension) may result from differences of NA and DA activity, and also potentially of a third transmission factor in the CNS (see below). As may be expected from any model, on closer examination there are more reasons for drawing the parallel with ADDH. But differences also become apparent. Foremost among potential differences would be the central nervous changes associated with hypertension. Let us first consider these and consider the possibility that they also may contribute to the picture which is the model of ADDH.

\subsection{Neurobiology of HyPertension: Participation In SHR Behavior?}

\subsubsection{Noradrenaline $(N A)$}

First of all there is the major contribution of NA activity to hypertension. An analysis of the content of a limited number of brain nuclei in the genetically hypotensive mouse showed increases of NA in the A1, A2, A6 nuclei, the anterior and posterior hypothalamus and septum. The comparison was drawn with both randomly bred and hypertensive animals (Denoroy et al., 1985). Pharmacological studies show that both the alpha agonist clonidine (which decreases the firing of NA cells) and the neuroleptic chlorpromazine (which has marked alpha antagonistic properties) have hypotensive effects in the SHR. In contrast the stimulation of supersensitive alpha receptors results in hypertension (Cerrito et al., 1984; Peroutka and Snyder, 1980).

Electrophysiological work broadly supports this inverse relationship between parameters of NA activity and blood pressure. SHRs have more slow firing neurones in the noradrenergic A6 nucleus than WKY control rats. Even in normal rats as the blood pressure rises the firing of A6 neurones decreases (Olpe et al., 1985). Two crucial areas for blood pressure control are the posterior hypothalamus and the nucleus of the solitary tract (NTS). In the former, an important area for sympathetic regulation, NA release is reduced in the SHR (Tuomisto et al., 1983) despite there being an apparent increased NA 
innervation during development (Winternitz et al., 1984). In the latter area 6-OHDA lesion renders blood pressure labile and electrolytic, nonspecific damage further abolishes the baroreceptor reflex (review, Reis and Talman, 1984). This latter result implies that there is an additional involvement of a non-NA transmitter.

\subsubsection{Glutamate, neuropeptide $Y$ and serotonin}

One good candidate for the "non-NA" modulation of hypertension, and in particular the baroreceptor reflex, is $l$-glutamate. Reis and Talman (1984) showed that administration of glutamate to the NTS induced hypotension. Another candidate is neuropeptide $Y$ which is reported to have similar effects to glutamate (and clonidine) after intracisternal infusion (Zini et al., 1984). Neuropeptide $Y$ is stored in the same neurons as adrenaline in the NTS and reticular system, where clonidine is claimed to act to reduce tension (Atkinson et al., 1984). Concentrations of neuropeptide $Y$ are lower in SHR than WKY rats in the cortex and brain stem (Maccarone and Jarrott, 1985).

The contribution of 5-HT to the characteristics of the SHR and/or central hypertension is difficult to pin down. Pressor and depressor effects have both been frequently reported after administration of the transmitter or precursor to normo- and hyper-tensive rats (Chalmers, 1982). The synthetic enzyme for 5-HT is abnormally active in the spinal cord and medulla of young but not older SHRs (Smith et al., 1979). At one month of age 5-HT levels are high in the hypothalamus of the SHR. By two months these are restricted to the posterior region and no differences are found in the fore or mid brains, pons/medulla or spinal cord (Howe et al., 1982). Indeed in contrast to the levels of the CA synthetic enzyme tyrosine hydroxylase, that of tryptophan hydroxylase outside the hypothalmus is no different even under conditions of stress (Ikeda et al., 1984). Evidence from electrical stimulation of the raphe (pressor response) and lesion with specific toxins (e.g. 5,7 ,dihydroxytryptamine: depressor response in SHR) is suggestive of a contribution to blood pressure changes from 5-HT innervation of the hypothalamus alone (Wolf et al., 1981; Chalmers, 1982).

\subsubsection{Dopamine $(D A)$}

Of the other transmitters whose activity may be associated with blood pressure changes (e.g. GABA, histamine, adrenaline: Tuomisto et al., 1983) DA is probably the most important. Thus, for example, after treatment with phencyclidine at a dose that induced acute hypertension, DA levels were found to fall and DA transmission in the NTS was enhanced (Bayorh et al., 1984). Indeed infusion of DA (icv $0.4 \mathrm{mg}$ ) leads to a decrease of blood pressure in rats and rabbits (Hutchinson and Mok, 1984).

Initially surprising was the finding of low striatal levels of DA in mice with high blood pressure (Denoroy et al., 1985). Alone this result does not inform us about DA activity. But it may be taken as consistent with the result of phencyclidine (above) which enhanced DA transmission. This interpretation is also consistent with the report that kainic acid lesions of the neostriatum lead to hypertension and tachycardia (Wu et al., 1984). Curiously the neostriatum was the one area found to show increased levels of neuropeptide $Y$ in the SHR with respect to WKY rats (Maccorone and Jarrott, 1985). These changes are in a region of the brain well situated for affecting the activity and reactivity of animals.

What about other brain regions? The apparent difference between the effects of DA in the neostriatum and the brain stem is mirrored within the hypothalamus. One group has reported a reduced release of DA from the posterior hypothalmus of SHRs but the opposite from the anterior region (Dietl et al., 1981; Tuomisto et al., 1983). Therefore it would be unwise to speculate or to generalize about CA changes in other brain regions (e.g. septum). Finally the potential involvement of the neocortices should not be overlooked. Areas such as the cingulate (Burns and Wyss, 1985) and insular cortex (Ullan, 
1983) are involved in vasomotor regulation (e.g. electrical stimulation studies), are directly connected with known blood pressure control centers (e.g. posterior hypothalamus and NTS) and receive major NA and DA innervation. Both regions are involved in the integration of sensory information as well as the organization of motor responses.

\subsection{The Link with Behavior and Cognition}

Is there a connection between blood pressure changes and cognitive function? Certainly in some forms of hypertension in man (e.g. high renin, as in the pituitary of SHRs: Naruse et al., 1985) psychological symptoms of sensitivity, hostility and psychotic thought disorder can occur (Thailer et al., 1985). Differences in vasomotor reactivity and in regional cerebral blood flow have been reported in ADDH-subjects (Butter et al., 1984; Lou et al., 1985). In both studies methylphenidate treatment normalised both of these anomalies and the children showed improved indices of learning and activity. Are there parallels in the animal model? Certainly SHRs are highly sensitive to sensory stimulation as shown by measures of heart rate and blood pressure (Hallbach and Folkow, 1974; Yamori et al., 1969). Further, slow electrical activity in the hippocampus has been reported to be associated with sympathetic and pressor effects whereas fast activity was associated with parasympathetic activity and the lowering of blood pressure (Toru and Kawamura, 1960). There is a large literature on the potential relationship between rhythmic slow activity in the hippocampus and the attention-related processing of information (e.g. review Oades, 1982a).

What are the behavioral features of the SHR rat? Broadly speaking their increased levels of activity and reactivity recall the similar features of rats with non-specific damage of the DA and non-DA elements of the A10 area (Gaffori et al., 1980; Le Moal et al., 1976). In the open field SHRs can show both increased motor activity and exploratory investigation of novel stimuli (Knardahl and Sagvolden, 1979; McCarty and Kirby, 1982). This is particularly marked in the center of an open field whereas WKY rats are more active around the edges (Hard et al., 1985, Table IV). These changes were correlated with individual blood pressure levels. Sutterer and coworkers (1984) also found a considerable increase of rearing in SHRs to sudden changes of light $(500 \mathrm{~W})$ or sound $(96 \mathrm{~dB})$ stimulation. But the amplitude and duration of the immobility response ( $6 \mathrm{sec}$ of a $95 \mathrm{~dB}$ bell) was shorter than that for either WKY or normotensive rats (Hard et al., 1985). Thus both hypertensive rats and humans (Brod, 1963; Falkner et al., 1979) can show a marked physiological response to environmental stimulation. However neither Whitehorn et al. (1983) nor Sutterer found a precise correlation with blood pressure. But a big problem with the SHR model is that the WKY "controls" also appear abnormal. They are unusually emotional, do not move or rear much, are not good at noticing novel stimuli, rapidly habituate motor responses and freeze in response to sudden environmental stimuli (Sutterer et al., 1980, 1981, 1984; Delini-Stula and Hunn, 1985; Hard et al., 1985). The question of appropriate controls for the behavioral characteristics of SHRs needs closer attention in future work.

Surprisingly SHRs are reported to be more active by day but show no differences with respect to normotensive rats by night (e.g. Sasagawa and Yamori, 1975; Hard et al., 1985). It is of interest to note in passing that a similar increase in daytime activity was the unexpected and, as yet, unexplained result of grafting DA containing cells into the nucleus accumbens of rats with A10-6-OHDA lesions (Dunnett et al., 1984). It would be of value to make more comparisons of circadian rhythms of activity in both the model and the clinical condition. The importance would lie in the study of the functional correlates of activity in different transmitter systems. But deeper lying causal connections may not be found. Thus Hendley and coworkers (1983) did not find a genetic link for hyperactivity to the hypertensive gene system of the SHR.

\subsection{The SePtum?}

Changes of exploratory motor behavior, sensory responsiveness and active avoidance acquisition of the SHR are not unlike those recorded in normal rats after electrolytic or 
6-OHDA lesion of the A10 projection region of the septum (Clody and Carlton, 1969; Chafetz et al., 1980; Oades et al., 1985a). SHRs are hyper-responsive to noncontingent electrical footshock (Knardahl and Sagvolden, 1982). Such an increase of sensitivity may contribute to the facilitation of acquisition of an active and Sidman avoidance tasks (Knardahl and Sagvolden, 1982; Sutterer et al., 1980; Takaori et al., 1972).

Remembering that there is a potential role for glutamate and neuropeptide $Y$ in hypertension, it is worth recalling that there is a major glutamergic (or aspartergic) input to the septum where there is also a moderate neuropeptide $Y$ innervation.

A further parallel can be mentioned emphasizing specific chemical lesions in normal animals. SHRs learned a rewarded alternation faster than normotensive controls (Low $e t$ al., 1984). A similar result was recorded for mice with septal-6-OHDA damage that resulted in increased acetyl choline activity in the hippocampus (Galey et al., 1984). Oades and colleagues (1985a; Fig. 2) have reported that the depletion of septal DA can alter the time course for learning a conditioned blocking task on which performance is claimed to reflect selective attentional function (Mackintosh, 1975). On this task impaired attentional performance reveals itself in animals learning about redundant stimuli (i.e. impaired attentional control) and thus in this special case learning the task faster than controls. It would be interesting to know how ADDH subjects would perform on such a task.

The septal area that receives a copious innervation from NA and DA fibers would seem to be worthy of closer investigation in the SHR. Further reason for such study is that during development, changes of activity of angiotensin converting enzyme are reported to be particularly marked in the septum (cf developmental time course for ADDH: Chevillard et al., 1984). Angiotensin II promotes drinking in the change of events arising after a drop of blood pressure. The septum is one site that is particularly sensitive to this peptide (Epstein et al., 1970). Injections of the peptide to the septum elicit drinking. There are high levels of angiotensin II in the septum and hypothalamus (Israel et al., 1984) and the adjacent stria terminalis and medial preoptic area (Weyhenmeyer and Phillips, 1982). Further there are high levels of radioligand binding in the septum, hypothalamus and neostriatum (Petersen et al., 1984). Angiotensin II excites septal neurons (Huwyler and Felix, 1980) and stimulates the release of NA (Langer, 1978) and DA (Simmonnet and Giorguieff-Chesselet, 1979).

With respect to the SHR there are reports of increased levels of angiotensinogen in a number of brain regions (Naruse et al., 1985) and less angiotensin converting enzyme, particularly in the cerebral blood vessels (Kobayashi et al., 1985). Interference with the breakdown of angiotensin II heightens pressor responses (Wright et al., 1985). Elsewhere it has been shown that the amount of CA released per impulse is higher in the SHR (Nilsson et al., 1985). As angiotensin II is one of several factors that can also affect the quantal release of NA (Vanhoutte et al., 1981) it seems appropriate that the consequences of anomalous CA activity in the septum should form one important direction of research into ADDH-like features modelled by the SHR.

Finally it is appropriate to record that there is a well known syndrome of hyperreactivity that follows lesion of the septum (Brady and Nauta, 1953). This syndrome is attenuated by activity of the gonadal steroid estrogen (Iovino et al., 1983). (Estrogen as well as being the most abundant gonadal steroid in females is synthesized in males and is present as a functional metabolite of testosterone in some limbic sites.) The effect of estrogen is of interest for three reasons. Firstly estrogen can modulate DA receptor activity rather like a DA antagonist (Joyce et al., 1984) and hence can modulate DA-mediated locomotion. Secondly estrogen tends to decrease responsiveness to angiotensin II and its binding in the preoptic-septal region (Fregly et al., 1985; Jonklaas and Buggy, 1985). Thirdly the natural changes of hormone levels at puberty could, speculatively, lead to or contribute to the change between ADD with hyperactivity in children and the adult residual syndrome with reduced activity.

Thus in view of the marked developmental changes, the effects of both principle CAs and the change of responsiveness that this brings, it is suggested that the function of specific transmitter systems of the septum and related structures of the limbic system, 
particularly in the SHR, may be crucial to an improved understanding of the ADDH syndrome.

\section{Conclusions}

It is naturally a difficult task to try to generalize on the ADDH condition where diagnostic practice has not been consistent and diagnosed subjects show highly variable measures on both cognitive tests and in neurochemical assays. From the research point of view what is needed are correlations of test performance (rather than mere clinical impression) with indicators of transmitter metabolism in controlled experiments using larger groups of subjects than has usually been the practice. What are the effects of treatments on learning and CA metabolism in normal and ADDH subjects?

There are two clinical conditions associated with the hyperactive syndrome. One of these (ADDH) portrays two major clusters of symptoms (attentional and motor disturbance) that seem to be both functionally and causally independent. In the ADDH condition there are, at least, two groups (psychostimulant responders and nonresponders), one of which, the responders, can show two effects of drug treatment on DA metabolism. Stimulants may raise, lower or decrease normal levels of HVA. In each case levels of MHPG fall. In view of this complexity it is little wonder that nondiscriminating pharmacological treatments have not proved highly successful in correcting maladaptive responsiveness, socialization and performance in ADDH subjects.

The results of current therapeutic strategies and studies of animal models suggest there is a double anomaly in NA and in DA metabolism. Neither serotonin nor GABA metabolism seem to be involved to any major extent. But since the ratios of CA metabolites remain anomalous even in responders, the possibility of a third neurochemical change is raised. Further animal studies are required both of the symptom, as produced by specific chemical brain lesion, and of the syndrome, as shown in animal strains. There are clues from such studies that CA interactions in the septum could be a source of the anomaly. With relatively few studies of the cognitive performance of the SHR on tasks of experimental psychology, information on how well this model fits the clinical picture is still lacking. How do animal models (e.g. SHR) respond on cued tasks, partial reinforcement and what sort of errors do these animals make on search-vigilance tasks? A comparison of such results with the effects of damage to specific septal neurotransmitter systems (e.g. 6-OHDA, ibotenic acid) on responding in similar tasks might be illuminating.

In animals the "typical" stimulants facilitate the release of CAs, improve incentive learning and assist in "tuning" the degree of stimulus selection and initiation or "switching" of the appropriate response: I refer here to fundamental roles that have been postulated for NA and DA transmission respectively (cf Beninger, 1983; Oades, 1985). In ADDH-subjects these agents modulate the utilization of CAs and help subjects to slow down and concentrate, for a while. Perhaps the use of atypical stimulants (e.g. the ergolines) that have both adrenergic and dopaminergic agonist properties combined with psychotherapeutic training of cognitive strategies would help to produce a longer lasting more favorable response.

\section{Summary}

An attention deficit disorder with hyperactivity in children (ADDH) is now recognized in most countries although diagnostic practices differ. Evidence is presented to show that the two cardinal symptoms of poor attentional performance and high motor activity may be functionally and causally separate. Both are temporarily relieved in a proportion of subjects that respond to psychostimulants. Beneficial treatment decreases noradrenergic metabolism and normalizes variable levels of dopaminergic metabolism. Parallels are drawn with other clinical syndromes arising from changed catecholaminergic activity and with behavioral interpretations of the result of damage to the dorsal noradrenergic bundle and dopaminergic A10 nucleus. Prognosis of ADDH subjects after treatment remains 
poor. There may be a further defect of neurotransmitter metabolism in the ADDH syndrome. Research strategies are suggested based on the neurobiological correlates of the cognitive style of ADDH subjects and septal function in the animal model of the hypertensive rat.

\section{Acknowledgement}

This work was in part supported by the Channel 10 Childrens Medical Research Foundation of South Australia.

\section{References}

Angrist, B., Rotrosen, J. and Gershon, S. (1980) Responses to apomorphine and amphetamine and neuroleptics in schizophrenic subjects. Psychopharmac. 67, 31-38.

Antelman, S. M., EichleR, A. J., Black, C. A. and Kocun, D. (1980) Interchangeability of stress and amphetamine sensitisation. Science 207, 329-331.

Archer, T., Frederiksson, A., Jonsson, G., Lewander, T., Mohammed, A., Ross, S. B. and Soderberg, U. (1986) Central noradrenaline depletion antagonizes aspects of $d$-amphetamine-induced hyperactivity in the rat. Psychopharmac. 88, 141-146.

Atkinson, J., Sonnay, M. and Boillat, N. (1984) Changes in central monoaminergic function during chronic treatment with clonidine in the spontaneously hypertensive rat. Eur. J. Pharmac. 106, 613-617.

AXELROD, J. (1970) Amphetamine: metabolism, physiological disposition and its effect ofn catecholamine storage In: Amphetamines and Related Compounds, pp. 207-216. Eds. E. Costa and S. GaRRA TINI. Raven Press: N.Y.

Ballinger, C. T., Varley C. K. and Nolen, P. A. (1984) Effects of methylphenidate on reading in children with attention deficit. Am. J. Psychiat. 141, 1590-1593.

Bareggi, S. R., Becker, R. E., Ginsberg, B. E. and Genovese, E. (1979) Neurochemical investigation of an endogenous model of the "hyperkinetic syndrome" in a hybrid dog. Life Sci. 24, 481-488.

BarkLeY R. A. (1982) Hyperactive Children: a Handbook for Diagnosis and Management. J. Wiley \& Sons Chichester.

Barrett, R. J. and Lokhandwala, M. F. (1983) Central and peripheral dopaminergic mechanisms in the cardiavascular actions of pergolide in neurogenic hypertensive dogs. Eur. J. Pharmac. 96, 211-226.

Baumeister, A. and Frye, G. D. (1985) The biochemical basis of the behavioural disorder in the Lesch-Nyhan syndrome. Neurosci. Biobehav. Rev. 9, 169-178.

Bayorh, R. A., Zukowska-Grojec Z., Palkovits, M. and Kopin, I. J. (1984) Effect of phencyclidine (PCP) on blood pressure and catecholamine levels in discrete brain nuclei. Brain Res. 321, 315-318.

Beninger, R. J. (1983) The role of dopamine in locomotor activity and learning. Brain Res. Rev. 6, 173-196.

Bhagavan, H. N., Coleman, M. and Coursin, D. B. (1975) The effect of pyridoxine hydrochloride on blood serotonin and pyridoxal phosphate contents in hyperactive children. Pediatrics 55, 437-441.

BRADLEY, C. (1937) The behavior of children receiving benzedrine. Am. J. Psychiat. 9, 577-585.

BRADY, J. V. and NAUTA, W. J. H. (1953) Subcortical mechanisms in emotional behavior: affective changes following septal forebrain lesions in the albino rat. J. comp. physiol. Psychol. 46, 339-346.

Breese, G. R., Baumeister, A. A., McCown, T. J., Emerick, S., Frye, G. D., Crotty, K. and Mueller, R. A. (1984) Behavioral differences between neonatal and adult 6-hydroxydopamine treated rats to dopamine agonists: relevance to neurological symptoms in clinical syndromes with reduced brain dopamine. J. Pharmac. exp. Ther. 231, 343-353.

BroD, J. (1963) Haemodynamic basis of acute pressor reactions and hypertension. Br. Heart 25, 227-245.

Buchsbaum, M. S., Haier, R. J. Sostek, A. J., Weingartner, S., Zahn, T. P., Siever, L. J., MurPhy, D. L. and BroDY, L. (1985) Attention dysfunction and psychopathology in college men. Arch. gen. Psychiat. 42, $354-360$.

Burks, H. F. (1964) Effects of amphetamine therapy on hyperkinetic children. Arch. gen. Psychiat. 11, $604-609$.

BURNS, S. M. and WYSs, J. M. (1985) Involvement of the anterior cingulate cortex in blood pressure control. Brain Res. 340, 71-77.

Butter, H. J., Lapierre, Y., Firestone, P. and Blank, A. (1984) Efficacy of ACTH 4-9 analog, methylphenidate and placebo on attention deficit disorder. Archs. Neurol. 8, 661-664.

Callaway, E. and Halliday, R. (1982) The effect of attentional effort on visual evoked potential N1 latency. Psychiat. Res. 7, 299-308.

Capute, A. J., Niedermeyer, E. F. L. and Richardson, F. (1968) The electroencephalogram in children with minimal brain dysfunction. Pediatrics 41, 1104-1114.

Caresia, L., Punetti, L., Besana, L., Bartoselli, F., Cazullo, A. G., Musetti, L. and Scarone, S. (1984) EeG and clinical findings during pemoline treatment in children and adults with attention deficit disorder. Neuropsychobiol. 11, 158-167.

CAREY, R. J. (1982) Septal lesions enhance hyperactivity induced either by amphetamine or lesions of the nucleus accumbens septi. Behav. Brain Res. 5, 43-52.

Cerrito, F., Martire, M. and Preziosi, P. (1984) Long-term treatment with clonidine and a-receptors in the brain of normotensive rats. Brain Res. 321, 45-54.

Chafetz, M. D., Thompson, R. G., Evans, S. H. and Gage, F. H. (1980) Biochemical specificity of septal hyperreactivity: a behavioral discrimination. Behav. Brain Res. 1, 27-38.

Chalmers, J. P. (1982) Central serotonin nerves and control of blood pressure. Proc. Aust. Physiol. Pharmac. Soc. 13, 6pp.

Chevillard, C., Niwa, M. and SaAvedra, J. M. (1984) Angiotensin converting enzyme in discrete forebrain areas of spontaneously hypertensive rats. Brain Res. 309, 389-392. 
Clark, C. R., Geffen, L. B. and Gefren, G. M. (1984) Monoamines in the control of state dependent cortical functions: evidence from studies of selective attention in animals and humans. Neurol. Neurobiol. 12, 487-502.

Clody, D. E. and Carlton, P. L. (1969) Behavioral effects of lesions of the medial septum. Physiol. Psychol. 67, 344-351.

Cole, J. O. (1978) Drug therapy of adult minimal brain dysfunction. McClean Hospital J. 3, 37-49.

Coleman, M. (1971) Serotonin concentration in whole blood of hyperactive children. J. Pediat. 78, 985-990.

Commissiong, J. W. (1985) Monoamine metabolites: Their relationship and lack of relationship to monoaminergic neuronal activity. Biochem. Pharmac. 34, 1127-1131.

ConNERs, C. K. (1972) Stimulant drugs and cortical evoked responses. In: Drugs, Development and Cerebral Function, pp. 179-199. Eds. W. L. SMITH and C. C. Thomas. Springfield, Illinois.

Conners, C. K. (1973) Rating scales for use in drug studies with children. Psychopharmac. Bull. (special issue) 24-29.

Conners, C. K. and Wells, K. C. (1979) Hyperactivity in Children. Univ. Park Press: Baltimore.

Conners, C. K., Rothschild, G., Eisenberg, L., Schwartz, L. S. and Robinson, E. (1969) Dextroamphetamine sulfate in children with learning disorders: effects on perception, learning and achievement. Arch. gen. Psychiat. 21, 182-190.

Costall, B., Hui, S-C. G. and NAYLoR, R. J. (1980) The basal locomotor activities of rats dictate the intensity of behavioral change following mesolimbic denervation. Neurosci Letts. 5, (suppl.) 461.

Crider, A., Solomon, P. R. and McMahon, M. A. (1982) Disruption of selective attention in the rat following chronic $d$-amphetamine administration: relationship to schizophrenic attention disorder. Biol. Psychiat. 17, 351-361.

Delini-Stula, A. and HunN, C. (1985) Neophobia in spontaneous hypertensive (SHR) and normotensive control (WKY) rats. Behav. Neur. Biol. 43, 206-211.

Denoroy, L., Sautel, M., Schlager, G., Sacquet, J. and Sassard, J. (1985) Catecholamine concentrations in discrete brain nuclei and sympathetic tissues of genetically hypertensive mice. Brain Res. 340, 148-150.

Dews, P. B. and DeweEse, J. (1977) Schedules of reinforcement. In: Handbook of Psychopharmacology, Vol. 7, Principles of Behavioral Pharmacology, pp. 107-150. Eds. L. L. IVERSEN, S. D. IverSen and S. H. SNYDER. Academic Press: N.Y.

Dietl, H., Eisert, A., Kraus, A. and Philippu, A. (1981) The release of endogenous catecholamines in the cat hypothalamus is affected by spinal transection and drugs which change the arterial blood pressure. J. Autonom. Pharmac. 1, 279-286.

DunNett, S. B., Bunch, S. T., GAGE, F. H. and Bjorklund, A. (1984) Dopamine rich transplants in rats with 6-OHDA lesions of the ventral tegmental area. I. Effects on spontaneous and drug-induced locomotor activity. Behav. Brain Res. 13, 71-82.

Dykman, R. A., Ackerman, P. T. and McCray, D. D. (1980) Effects of methylphenidate on selective and sustained attention in hyperactive reading-disabled and presumably disordered boys. $J$. nerv. ment Dis. 168, 745-752.

Dykman, R. A., Ackerman, P. T. and Oglesby, D. M. (1979) Selective and sustained attention in hyperactive, learning disabled and normal boys. J. nerv. ment Dis. 167, 288-297.

Elchisak, M. A., Polinsky, R. J., Ebert, M. M., Powers, K. J. and Kopin, I. J. (1978) Contribution of plasma homovanillic acid (HVA) to urine and cerebrospinal fluid HVA in the monkey and its pharmokinetic disposition. Life Sci. 23, 2339-2348.

Elkins, R. N., Rapoport, J. L., ZahN, T. P., Buchsbaum, M. S., Weingartner, N., Kopin, I. J., Langer, D. and Johnson, C. (1981) Acute effects of caffeine in normal prepubertal boys. Am. J. Psychiat. 138, 178-183.

Elliott, L., Halliday, R. and Callaway, E. (1978) Brain event-related potentials: contributions to research in learning disabilities. In: Progress in Learning Disabilities, pp. 121-144. Ed. J. MYKLEBust. Grune \& Stratton: NY.

Epstein, A. N., Fitzsimmons, J. T. and Rolls, B. J. (1970) Drinking induced by injections of angiotensin into the brain of the rat. $J$. Physiol. 210, 457-474.

Epstein, L. C., Lasagna, L., Conners, C. K. and Rodriguez, A. (1968) Correlation of dextroamphetamine excretion and drug response in hyperkinetic children. J. nerv. ment. Dis. 146, 136-146.

Falkner, B., Onesti, G. Angelakos, E. T., Fernandes, M. and Langman, C. (1979) Cardiovascular response to mental stress in normal adolescents with hypertensive parents. Hypertension 1, 23-30.

Ferguson, H. B., Pappas, B. A., Trites, R. L., Peters, D. A. V. and Taub, H. (1981) Plasma free and total tryptophan, blood serotonin and the hyperactivity syndrome: no evidence for the serotonin deficiency hypothesis. Biol. Psychiat. 16, 231-238.

FiNCH, M. (1968) EEG classification of psychoactive compounds: a review and theory of behavioral association. In: Efron Public Health Service publ. no 1936, Psychopharmacology, a Review of Progress 1957-1967. Washington, D.C.

Fishman, R. H. B., Feigenbaum, J. J., Yanal, J. and Klawans, H. L. (1983) The relative importance of dopamine and norepinephrine in mediating locomotor activity. Prog. Neurobiol. 20, 55-88.

Fregly, M. J., Rowland, N. E., Sumners, C. and Gordon, D. B. (1985) Reduced dipsogenic responsiveness to intracerebroventricularly administered angiotensin II in estrogen treated rats. Brain Res. 338, 115-121.

GAFFORI, O., LE MOAL, M. and STINUS, L. (1980) Locomotor hyperactivity and hypoexploration after lesion of the dopaminergic A10 area in the ventral mesencephalic tegmentum (VMT) of rats. Behav. Brain Res. 1, 313-329.

GaleY, D., DURKon, T., Sifakis, G. and JAFFARD, R. (1984) Improvement of spontaneous and acquired spatial behaviors after lesion of septal dopaminergic afferents in mice: possible relationships with hippocampal cholinergic activity. C.r. Acad. Sci. Paris 299, 681-686.

Gittelman, R. and Mannuzza, S. (1985) Diagnosing ADD-H in adolescents. Psychopharmac. Bull. 21, $237-242$. 
GLow, R. A. (1980) A validation of Conners TQ and a cross-cultural comparison of prevalence of hyperactivity in children. Human Psychopharmac. 1, 303-320.

Glow, R. A. and Glow, P. H. (1984) From trait to category of child behavior disorder; advances in the use of the Adelaide parent rating scale. Adv. behav. meas. Children 1, 175-216.

Glow, R. A., LANGe, R. V., Glow, P. H. and BuRnett, J. A. (1983) Cognitive and self-reported impulsiveness: comparison of Kagan's MFFT and Eysenck's EPQ impulsiveness measures. Personal. Individ. Diffs. 4, 179-187.

GoldberG, J. O. and Konstantareas, M. M. (1981) Vigilance in hyperactive children on a self-paced operant task. J. Child Psychol. 22, 55-63.

Goldstone, S. and Lhamon, W. T. (1976) The effects of haloperidol upon temporal information processing by patients with Tourette's syndrome. Psychopharmac. 50, 7-10.

GolinKo, B. E. (1982) Side effects of dexedrine in hyperactive children: operationalization and quantification in a short-term trial. Prog. Neuropsychopharmac. Biol. Psychiat. 6, 175-183.

GreEN, L. and Warschauer, D. A. (1981) A note on the "Paradoxical" effect of stimulants on hyperactivity with reference to the rate dependency effect of drugs. J. nerv. ment. Dis. 169, 196-198.

Gross, M. D. (1977) Improvement with L-DOPA in a hyperkinetic child. Dis. nerv. Syst. 38, 556.

HALlBaCH, M. and FolKow, B. (1974) Cardiovascular responses to acute mental "stress" in spontaneously hypertensive rats. Acta physiol. scand. 90, 684-698.

Halliday, R., Callaway, E. and Naylor, E. (1983) Visual evoked potential changes induced by methylphenidate in hyperactive children: dose-response effects. Electroenceph. clin. Neurophysiol. 55, 258-267.

Halliday, R., Callaway, E., Rosenthal, J. R. and Naylor, H. (1979) The effects of methylphenidate dosage on the visual evoked potential of hyperactive children. In: Human Evoked Potentials: Applications and Problems. Eds. D. Lehmann and E. Callaway. Plenum Press: N.Y.

Harcherik, D. F., Cohen, D. J., Ort, S., Paul, R., Shaywitz, B. A., Volkmar, F, R., Rothman, S. L. G. and Leckman, S. J. F. (1985) Computed tomographic brain scanning in four neuropsychiatric disorders of childhood. Am. J. Psychiat. 142, 731-734.

Hard, E., Carlsson, S. G., Jern, S., Larsson, K., Lindh, A-S. and Svensson, L. (1985) Behavioral reactivity in spontaneously hypertensive rats. Physiol. Behav. 35, 487-492.

Heath, R. G. (1966) Schizophrenia: biochemical and physiologic alterations. Int. J. Psychiat. 2, 597-674.

Hechtman, L. (1985) Adolescent outcome of hyperactive children treated with stimulants in childhood: a review. Psychopharmac. Bull. 21, 178-191.

Hechtman, S., Weiss, G. and Mitrakos, K. (1978) Hyperactive individuals as young adults: current and longitudinal electroencephalographic evaluation and its relation to outcome. Canad. med. Ass. J. 118 , 919-923.

Hellstrand, K. and ENGEL, J. (1980) Locomotor activity and catecholamine, receptor binding in adult normotensive and spontaneously hypertensive rats. $J$. Neur. Trans. 48, 57-63.

Helmeste, D. M. and SeEman, P. (1982) Amphetamine-induced hypolocomotion in mice with more brain D2 dopamine receptors. Psychiat. Res. 7, 351-359.

Hendley, E. D., Atwater, D. G., Myers, M. M. and Whitehorn, D. (1983) Dissociation of genetic hyperactivity and hypertension in SHR. Hypertension 5, 211-217.

Holcomb, P. J., Ackerman, P. T. and Dykman, R. A. (1986) Auditory event-related potentials in attention and reading disabled boys. Int. J. Psychophysiol. 3, 263-273.

Houslay, M. D., Tipton, K. F. and Youdim, M. B. H. (1976) Multiple forms of monoamine oxidase: fact and artifact. Life Sci. 17, 467-481.

Howe, P. L. C., Stead, B. H., Lovenberg, W. and Chalmers, J. P. (1982) Effects of central serotonin nerve lesions on blood pressure on normotensive and hypertensive rats. Clin. exp. Pharmac. Physiol. 9, 335-341.

Hulihan-Giblin, B., Hauger, R. L., Janowsky, A. and Paul, S. M. (1985) Dopaminergic denervation increases $3 \mathrm{H}(+)$-amphetamine binding in the rat striatum. Eur. J. Pharmac. 113, 141-142.

HuNT, R. D. (1982) Strategies for the study of the neurochemistry of attention deficit disorder. Schizophrenia Bull. 8, 236-251.

Hutchinson, J. S. and Mok, J. S. L. (1984) Neuropeptide abnormalities suggest a dopaminergic basis for high blood pressure in the spontaneously hypertensive rat. Clin. exp. Theory Practice, A6, (10-11) 2055-2058.

Huwyler, T. and Felix, D. (1980) Angiotensin II-sensitive neurons in septal areas of the rat. Brain Res. 195, $187-195$

Ikeda, M., Hirata, Y., Fujita, K., Shinzato, M., Takahashi, H., Yagyu, S. and Nagatsu, T. (1985) Effects of stress on release of dopamine and serotonin in the striatum of spontaneously hypertensive rats: an in vivo voltammetric study. Neurochem. Int. 6, 509-512.

INGRAM, T. T. S. (1956) A characteristic form of overactive behavior in brain damaged children. J. ment. Sci. 102, 550-558.

Iovino, M., Monteleone, P., Barone, P. and Steardo, L. (1983) Inhibition of septal hyperreactivity by testosterone and its reversion by an estrogen antagonist in weanling female rats. Neurosci. Letts. $\mathbf{4 0}$, 151-156.

IRELAND, W. W. (1877) On idiocy and imbecility. Churchill: London.

Israel, A., Correa, F. M. A., Nowa, M. and SaAvedra, J. (1984) Quantitative determination of angiotensin II binding sites in rat brain and pituitary gland by autoradiography. Brain Res. 322, 341-345.

JACKson, R. T. and Pelton, E. W. (1978) L-DOPA treatment of children with hyperactive behavior. Neurol. $28,331$.

Johnson, R., Pfefferbaum, A. and Kopell, B. S. (1985) P 300 and long-term memory: latency predicts recognition performance. Psychophysiol. 22, 497-507.

JONKLAAS, J. and BUGGY, J. (1985) Angiotensin-estrogen central interaction: localization and mechanism. Brain Res. 326, 239-249. 
Joyce, J. N., Montero, E. and Van Hartesveldt, C. (1984) Dopamine-mediated behaviors: characteristics of modulation by estrogen. Pharmac. Biochem. Behav. 21, 791-800.

KELLEY, W. N. and WYNGAARDEN, J. B. (1983) Clinical syndromes associated with hypoxanthine guanine phosphoribosyl transferase deficiency. In: The Metabolic Basis of Inherited Disease, pp. 1115-1143. Eds. J. B. Stanbury, J. B. Wynganaden and D. S. Frederickson, McGraw Hill: N.Y.

KLEE, S. H. and GARFINKEL, B. D. (1983) The computerized continuous peformance task: a new measure of inattention. J. abnorm. Child Psychol. 11, 487-495.

Klorman, R., Salzman, L. F., Pass, H. L., Borgstedt, A. D. and Dainer, K. B. (1979) Normalizing effects of methylphenidate on hyperactive children's vigilance performance and evoked potentials. Psychophysiol. 16, 23-29.

KNARDAHL, S. and SagVolden, T. (1979) Open field behavior of spontaneously hypertensive rats. Behav. Neur. Biol. 27, 187-200.

KNARDAHL, S. and SAgVolden, T. (1982) Two-way active avoidance behavior of spontaneously hypertensive: effects of intensity of discontinuous shock. Behav. Neur. Biol. 35, 105-120.

KNIGHTS, R. M. and HiNTON, G. G. (1969) The effects of methylphenidate (Ritalin) on the motor skills and behavior of children with learning problems. J. nerv. ment. Dis. 148, 643-653.

Kobayashi, H., Wada, A., IzUmi, F., TAKe, K. and Magnoni, M. S. (1985) Low activity of angiotensinconverting enzyme in cerebral microvessels of young spontaneously hypertensive rats. J. Neruochem. 4, $1318-1320$.

Kokkinidis, L. and ANISMAN, H. (1980) Amphetamine models of paranoid schizophrenia: an overview and elaboration of animal experimentation. Psychol. Bull. 88, 551-579.

Koob, G. F., Stinus, L. and Le Moal, M. (1981) Hyperactivity and hypoactivity produced by lesions to the mesolimbic dopamine system. Behav. Brain Res. 3, 341-359.

KopIN, I. J. (1978) Measuring turnover of neurotransmitters in human brain. In: Psychopharmacology: a Generation of Progress, pp. 1845-1847. Eds. M. A. Lipton, A. Dimascio and K. F. Killam. Raven Press: New York.

Kopin, I. J., Jimerson, D. C., Markey, S. P., Ebert, M. H. and Polinsky, R. J. (1984) Disposition and metabolism of MHPG in humans: application to studies in depression. Pharmacopsychiat. 17, 3-8.

KuPIETZ, S. S. (1976) Alterations it the vigilance performance of children receiving amitryptiline and methylphenidate pharmacotherapy. Psychopharmac. 50, 29-33.

Langer, D. H., Rapoport, J. L., Brown, G. L., Ebert, M. and Bunney, W. E. (1982) Behavioral effects of carbidopa/levodopa in hyperactive boys. J. Am. Acad. Child Psychiat. 21, 10-18.

LANGER, S. Z. (1978) Presynaptic receptors (commentary). Nature 275, 479-480.

LANGer, S. Z. and ARBilla, S. (1984) The amphetamine paradox in dopaminergic transmission. Trends in Pharmac. Sci. 5, 387-391.

Laufer, M. W., Denhoff, E. and Solomans, G. (1957) Hyperkinetic disorder in children's behavioral problems. Psychosom. Med. 19, 38-49.

Le Moal, M., Stinus, L. and Galey, D. (1976) Radiofrequency lesion of the ventral mesencephalic tegmentum: neurological and behavioral considerations. Expl Neurol. 50, 521-535.

Lesch, M. and NyHAN, W. L. (1964) A familial disorder of uric acid metabolism and central nervous function. Am. J. Med. 36, 561-570.

Lloyd, K. G., Hornykiewicz, O., Davidson, L., Shannak, K., Farley, I., Goldstein, M., Shibuya, M. KeLLEY, W. N. and Fox, I. H. (1981) Biochemical evidence of dysfunction of brain neurotransmitters in the Lesch-Nyhan syndrome. New Engl. J. Med. 305, 1106-1111.

Lou, H. C., Henriksen, L. and BruHN, P. (1985) Focal cerebral hypoperfusion in children with dysphasia and/or attention deficit disorder. Archs Neurol. 41, 825-829.

Louis, W. J., RABei, R., SJoerdsma, A. and SPECTOR, S. (1969) Inheritance of high blood presure in the spontaneously hypertensive rat. Lancet $i, 1035-1036$.

Low, W. C., Whitehorn, D. and Hendley, E. D. (1984) Genetically related rats with differences of hippocampal uptake of norepinephrine and maze performance. Brain Res. Bull. 12, 703-709.

MaAs, J. W. (1984) Relationships between central nervous system noradrenergic function and plasma and urinary concentrations of norepinephrine metabolites. In: Frontiers in Biochemical and Pharmacological Research in Depression, pp. 45-55. Eds. E. Usdin, M. AsBerg, L. BerTiLsson and F. SJOQvist. Raven Press: New York.

MaAs, J. W., Hattox, S. E., Greene, N. M. and Landis, D. H. (1979) 3-Methoxy-4-hydroxyphenylethyleneglycol production in human brain in vivo. Science 205, 1025-1027.

Maccorrone, C. and JARROTT, B. (1985) Differences in regional brain concentrations of neuropeptide $Y$ in spontaneously hypertensive (SH) and Wistar-Kyoto (WKY) rats. Brain Res. 345, 165-169.

MACKINTOSH, N. J. (1975) A theory of attention: variations in the associability of stimuli with reinforcement. Psychol. Rev. 82, 276-298.

Maclennan, A. J. and Maier, S. F. (1983) Coping and stress-induced potentiation of stimulant stereotypy in the rat. Science 219, 1091-1093.

Mannelli, M., Delitala, G., Laura De Feo, M., Maggi, M., Cuomo, S., Piazzini, M., Guazelli, R. and SERIO, M. (1984) Effects of different dopaminergic antagonists on bromocriptine induced inhibition of norepinephrine release. J. clin. Endocr. Metab. 59, 74-78.

Mannuzza, S. and Gittelman, R. (1984) The adolescent outcome of hyperactive girls. Psychiat. Res. 13, $19-29$.

Mattes, J. A., Boswell, L. and Oliver, H. (1984) Methylphenidate effects on symptoms of attention deficit disorder in adults. Arch gen. Psychiat. 41, 1059-1063.

MCCARTY, R. and KIRBY R. (1982) Spontaneous hypertension and open field behavior. Behav. Neur. Biol. 34, 450-452.

MCCONNELL, H. (1985) Catecholamine metabolism in the attention deficit disorder: implications for the use of amino acid precursor therapy. Med. Hypoth. 17, 305-313. 
Messiha, F. S. and Carlson, J. C. (1983) Behavioral and clinical profiles of Tourette's disease: a comprehensive review. Brain Res. Bull. 11, 195-204.

MillaRd, W. J. and Standish, L. J. (1982) The paradoxical effect of central nervous system stimulants on hyperactivity: a paradox unexplained by the rate dependent effect. $J$. nerv. ment. Dis. 170, 499-501.

MiLner, J. D. and WURTMAN, R. J. (1985) Tyrosine availability determines stimulus evoked dopamine release from rat striatal slice. Neurosci. Letts 59, 215-220.

Morales-Olivas, F. J., Palop, V., Rubio, V. and Esplugues, J. (1984) Hypotensive action and alpha adrenolytic properties of a new dopaminergic agonist CU 32-085 in the rat. Arch int. Pharmacodyn. Thér 272, 71-78.

Naruse, M., Naruse, K., McKenzie, J. C., Schelling, P. and Inagami, T. (1985) Regional distribution of renin and angiotensinogen in the brain of normotensive (WKY) and spontaneously hypertensive (SHR) rats. Brain Res. 333, 147-150.

Naylor, H., Halliday, R. and Callaway, E. (1985) The effect of methylphenidate on information processing. Psychopharmac. 86, 90-95.

Niflsen, J. A., Chapin, D. S. and MoOre, K. E. (1983) Differential effects of $d$-amphetamine, betaphenylethylamine, cocaine and methylphenidate on the rate of dopamine synthesis in terminals of nigrostriatal and mesolimbic neurons and on the efflux of dopamine metabolites into cerebroventricular perfusates of rats. Life Sci. 33, 1899-1907.

Nilsson, H., Ely, D., Friberg, P., Karlstrom, G. and Folkow, B. (1985) Effects of high and low sodium diets and the resistance vessels and their adrenergic vasoconstrictor fibre control in normotensive (WKY) and hypertensive (SHR) rats. Acta physiol. scand. 125, 323-332.

OADES, R. D. (1981) Dopaminergic agonistic and antagonistic drugs in the ventral tegmentum of rats inhibit and facilitate changes of food search behaviour. Neurosci Letts 27, 75-80.

OADES, R. D. (1982a) Attention and Schizophrenia: Neurobiological Bases. Pitman Press: London.

OADES, R. D. (1982b) Search strategies on a holeboard are impaired in rats with ventral tegmental damage: animal model for tests of thought disorder. Biol. Psychiat. 17, 242-258.

OADES, R. D. (1985) Role of noradrenaline in tuning and dopamine in switching between signals in the CNS Neurosci. Biobehav. Rev. 9, 261-282.

OAdes, R. D., REA, M. and TAGHzouti, K. (1985a) Modulation of selective processes in learning by neocortical and limbic dopamine: studies of behavioural strategies. In: Brain Plasticity, Learning and Memory, pp. 241-251. Eds. B. Will, P. Schmitt and J. C. Dalrymple-Alford. Plenum Press: N.Y.

Oades, R. D., Taghzouti, K., Simon, H. and Le Moal, M. (1985b) Dopamine-sensitive alternation and collateral behaviour in a Y-maze: effects of $d$-amphetamine and haloperidol. Psychopharmac. 85, 123-128.

Oades, R. D., Taghzouti, K., Rivet, J. M., Simon, H. and Le Moal, M. (1986a) Locomotor activity on relation to dopamine and noradrenaline in the nucleus accumbens, septal and frontal areas: a 6-hydroxydopamine study. Neuropsychobiol., in press.

Oades, R. D., Rivet, J-M., Taghzouti, K., Kharouby, M., Simon, H. and Le Moal, M. (1986b) Attentional blocking is delayed by depletion of septal dopamine but remains attenuated after frontal depletion. submitted.

Olpe, H-R., Berecek, K., Jones, R. S. G., Steinmann, M. W., Sonnenburg, Ch. and Hofbauer, K. G. (1985) Reduced activity of locus coeruleus neurons in hypertensive rats. Neurosci. Letts. 61, 25-29.

OUNSTED, C. (1955) The hyperkinetic syndrome in epileptic children. Lancet ii, 123-128.

PeroutKa, S. J. and SNYDER, S. H. (1980) Relation of neuroleptic drug effects at brain dopamine, serotonin, alpha adrenergic and histamine receptors to clinical potency. Am. J. Psychiat. 137, 518-522.

Petersen, E. P., Camara, C. P., Abhold, R. H., Wright, J. W. and Harding, J. W. (1984) Charcterization of angiotensin binding to gerbil brain membranes using 125-I-angiotensin III as the radioligand. Brain Res. 321, 225-235.

RapOPORT, J., QuinN, P., SCRIBNAU, N. and MURPhy, D. L.. (1974) Platelet serotonin of hyperactive school-age boys. Br. J. Psychiat. 125, 138-140.

Rapoport, J. L., Zametkin, A., Donnelly, M. and Ismond, D. (1985) New drug trials in attention deficit disorder. Psychopharmac. Bull. 21, 232-236.

Rapoport, J., Buchsbaum, M., Weingartner, H., Zahn, T., Ludlow, C. and Mikkelsen, E. (1980) Dextroamphetamine: cognitive and behavioral effects in normal and hyperactive boys and normal men. Arch. gen. Psychiat. 37, 933-943.

Rapoport, J. L., Buchsbaum, M., Zahn, T., Weingartner, H., Ludlow C. and Mikkelsen, E. (1978) Dextroamphetamine: cognitive and behavioral effects in normal prepubertal boys. Science 199, $560-562$.

RAPPORT, M. D., Du PAul, D. J. and Smith, N. F. (1985) Rate dependency and hyperactivity: methylphenidate effects on operant responding. Pharmac. Biochem. Behav. 23, 77-83.

Raskin, L., Shaywitz, S., Shaywitz, B., Anderson, G. and Cohen, D. (1984) Neurochemical correlates of attention deficit disorder. Pediat. Clins N. Am. 31, 387-396.

Raskin, L. A., Shaywitz, B. A., Anderson, G. M., Cohen, D. J., Teicher, M. H. and Linakis, J. (1983) Differential effects of selective dopamine, norepinephrine or catecholamine depletion on activity and learning in the developing rat. Pharmac. Biochem. Behav. 19, 743-749.

Reimherr, F. W., Wender, P. H., Ebert, M. H. and WoOd, P. R. (1984) Cerebrospinal fluid homovanillic acid and 5-hydroxyindole acetic acid in adults with attention deficit disorder, residual type. Psychiat. Res 11, 71-78.

REIS, D. J. and Talman, W. T. (1984) Brain lesions and hypertension. In: Handbook of Hypertension, Vol 4: Experimental and Genetic Models of Hypertension, pp. 451-473. Ed. W. DE Jong. Elsevier: Amsterdam.

RoBbins, T. W. and SAHAKIAN, B. J. (1979) "Paradoxical" effects of psychomotor stimulant drugs in hyperactive children from the standpoint of behavioural pharmacology. Neuropharmac. 18, 931-950.

Roffler-Tarlov, S. and Graybiel, A. M. (1984) Weaver mutation has differential effects on the dopamine-containing innervation of the limbic and non-limbic striatum. Nature 307, 62-66. 
SAFER, D. J. and KRAGER, J. M. (1985) Prevalence of medication treatment for hyperactive adolescents. Psychopharmac. Bull. 21, 212-215.

Sanger, D. J. and Blackman, D. (1976) Rate-depedent effects of drugs: a review of the literature. Pharmac. Biochem. Behav. 4, 73-83.

SARA, S. J., GREKSCH G. and LEVIEL, V. (1984) Intracerebroventricular apomorphine alleviates spontaneous forgetting and increases cortical noradrenaline. Behav. Brain Res. 13, 43-52.

SASAGAWA, S. and YAMORI, Y. (1975) Quantitative analysis on the behavior of spontaneously hypertensive rats (SHR) and stroke-prone SHR, Jap. Heart J. 16, 313-315.

SCHEEL-KRUGER, J. (1971) Comparative studies of various amphetamine analogues demonstrating different interactions with the metabolism of catecholamines in the brain. Eur. J. Pharmac. 14, 47-59.

Sefgmller, J. E., Rosenbloom, F. M. and Kellew, W. N. (1967) An enzyme defect associated with sex-linked human neurological disorder and excessive purine synthesis. Science 155, 1682-1684.

Shapiro, A. K. and Shapiro, E. (1982) An update on Tourette syndrome. Am. J. Psychother. 26, 379-389.

SHAYwITZ, B. A., COHEN, D. J. and BOWERS, M. G. (1977) CSF monoamine metabolites in children with minimal brain dysfunction-evidence for alteration of brain dopamine. J. Pediatr. 90, 67-71.

ShaYwitZ, B. A., YAGER, R. D. and KLOPER, J. H. (1976) Selective brain dopamine depletion in developing rats: an experimental model of minimal brain dysfunction. Science 191, 305-308.

Shaywitz, B. A., Shaywitz, S. E., Byrne, T., Cohen, D. J. and Rothman, S. (1983) Attention deficit disorder: Quantitative analysis of CT. Neurol. 33, 1550-1503.

Shekim, W. O., Dekirmenjian, H. and Chapel, J. L. (1979) Urinary MHPG excretion in minimal brain dysfunction and its modification by $d$-amphetamine. Am. J. Psychiat. 136, 667-671.

ShekiM, W. O., JAVAID, J., DAvis, J. M. and Bylund, D. B. (1983) Urinary MHPG and HVA excretion in boys with attention deficit disorder and hyperactivity treated with $d$-amphetamine. Biol. Psychiat. 18, 707-714.

Shekim, W. O., Javaid, J., DekiRmenhian, H., Chapel, J. L. and David, J. M. (1982) Effects of $d$-amphetamine on urinary metabolites of dopamine and norepinephrine in hyperactive boys. Am. J. Psychiat. 139, 485-488.

SHEN, Y-C. and WANG, Y-F. (1984) Urinary 3-methoxy-4-hydroxyphenylglycol sulfate excretion in seventythree schoolchildren with minimal brain dysfunction syndrome. Biol. Psychiat. 19, 861-871.

ShetTy, T. and Chase, T. (1976) Central monoamines and hyperkinesis of childhood. Neurol. 26, $1000-1002$.

Silverstein, F. S., Johnston, M. V., Hutchinson, R. J. and Edwards, N. L. (1985) Lesch-Nyhan syndrome: CSF neurotransmitter abnormalities. Neurol. 35, 907-911.

Simon, H. (1981) Neurones dopaminergiques A 10 et systeme frontal. J. Physiol. Paris 77, 81-95.

Simon, H., Scatton, B. and Le Moal, M. (1980) Dopaminergic A 10 neurones are involved in cognitive functions. Nature 286, 150-151.

SimmonNET, G. and GiorguiefF-Chesselet, M. F. (1979) Stimulating effect of angiotensin II on the spontaneous release of newly synthesized 3H-dopamine in rat striatal slices. Neurosci. Letts 10, 153-158.

SMith, M. L., Browning, R. A. and MYers, J. H. (1979) In vivo rate of serotonin synthesis in brain and spinal cord of young spontaneously hypertensive rats. Eur. J. Pharmac. 53, 301-305.

SMith, R. D., COOPER, B. R. and Breese, G. R. (1983) Growth and behavioral changes in developing rats treated intracisternally with 6-hydroxydopamine: evidence for involvement of brain dopamine. J. Pharmac. exp. Ther. 185, 609-619.

SOLANTO, M. V. (1984) Neuropharmacological basis of stimulant drug action in attention deficit disorder with hyperactivity: a review and a synthesis. Psychol. Bull. 95, 387-409.

Solanto, M. V. and ConNers, C. K. (1982) A dose-response and a time-action analysis of autonomic and behavioral effects of methylphenidate in attention deficit disorder with hyperactivity. Psychophysiol. 19, 658-667.

SPRAGUe, R. L. and Sleator, E. K. (1977) Methylphenidate in hyperactive children: differences in dose effects in learning and social behavior. Science 198, 1274-1276.

STAHL, S. M. and BERGER, P. A. (1982) Neuroleptic effects in Tourette syndrome predict dopamine excess and acetyl choline deficiency. Biol. Psychiat. 17, 1047-1053.

Steinhausen, H. C. and Goebel, D. (1985) The validity of the hyperkinetic syndrome: A study in child psychiatric clinical attenders. Eur. Arch. Psychiat. Neurol. 235, 122-128.

Sternberg, D. E., Heninger, G. R. and Roth, R. H. (1983) Plasma homovanillic acid as an index of brain dopamine metabolism: enhancement with debrisoquin. Life Sci. 32, 2447-2452.

Stewart, M. A., Pitts, F. N., Graig, H. G. and Dieruf, W. (1966) The hyperactive child syndrome. Am. J. Orthopsychiat. 36, 861-867.

SuRwiLl, W. W. (1981) Cortical evoked potentials in Gilles de la Tourette's syndrome: a single case study. Psychiat. Res. 4, 31-38.

Sutterer, J. R., Devito, W. J. and Rykaszewski, I. (1981) Developmental effects of a two way shuttle box avoidance in the spontaneously hypertensive and normotensive rat. Devl Psychobiol. 14, 405-414.

Sutterer, J. R., Perry, J. and Devito, W. (1980) Two-way shuttle box and level press avoidance in the spontaneously hypertensive and normotensive rat. J. comp. physiol. Psychol. 94, 155-163.

SutTerer, J. R., StONEY, C. M. and SANFILlipo, M. (1984) Is the hypertensive rat really hyperreactive? Hypertension 6, 868-876.

Swann, A. C., MaAs, J. M., Hattox, j. E. and Landis, H. (1980) Catecholamine metabolites in human plasma as indices of brain functions: Effects of debrisoquin. Life Sci. 25, 1857-1862.

Sykes, D. H., Douglas, V. I. and Morgernstern, G. (1972) The effect of methylphenidate (Ritalin) on sustained attention in hyperactive children. Psychopharmac. 25, 262-274.

Sykes, D. H., Douglas, V. I. and MORgernstern, G. (1973) Sustained attention in hyperactive children. $J$. Child Psychol. Psychiat. 14, 213-220.

Sykes, D. H., Douglas V. I., WeISS, G. and Minde, K. K. (1971) Attention in hyperactive children and the effect of methylphenidate (Ritalin). J. Child Psychol. Psychiat. 12, 129-139. 
SzPORNY, L. and Garog, P. (1961) Investigations into the correlations between monoamine oxidase inhibition and other effects due to methylphenidate and its stereoisomers. Biochem. Pharmac. 8, 263-268.

TAKAORI, S., TANAKA, C. and OKAMOTO, K. (1972) Relationship between behavior and brain monoamines in spontaneously hypertensive rats. In: Spontaneous Hypertension, pp. 88-92. Ed. K. OKaMoto. Igaku Shoin: Tokyo.

Taylor, M. A. and Abrams, R. A. (1975) Critique of the St Louis psychiatric research criteria for schizophrenia. Am. J. Psychiat. 132, 1276-1280.

Thailer, S. A., Friedman, R., Harshfield, G. A. and Pickering, T. G. (1985) Psychologic differences between high-, normal- and low-renin hypertensives. Pschosom. Med. 47, 294-297.

THORLEY, G. (1984) Hyperkinetic syndrome of childhood: clinical characteristics. Br. J. Psychiat. 144, 16-24.

TORU, S. and KAWAmURA, H. (1960) Effects of amygdaloid stimulation on blood pressure and electrical activity of the hippocampus. Jap. J. Physiol. 10, 374-384.

TUKE, D. H. (1892) A Dictionary of Psychological Medicine, Vol. 1. Churchill: London.

TunniclifF, G., Welborn, K. L. and HeAD, R. A. (1984) The GABA/benzodiazepine receptor complex in the nervous system of a hypertensive strain of rat. Neurochem. Res. 9, 1033-1038.

Tuomisto, L., Yamatodani, A., Dietl, H., Waldmann, U. and Philippu, A. (1983) In vivo release of endogenous catecholamine, histamine and GABA in the hypothalamus of spontaneously hypertensive rats. Naunyn-Schmiedebergs Arch. Pharmak. 323, 183-187.

ULLAN, J. (1983) Interconnections between centres involved in vasomotor regulation: a neuroanatomical study in the rat. Neurosci. Letts 381, (suppl.).

Vanhoutte, P. M., Verbeuren, T. J. and WebB, R. C. (1981) Local modulation of adrenergic neuroeffector function in the blood vessel wall. Physiol. Rev. 61, 151-247.

Varley, C. K. (1985) A review of studies of drug treatment efficacy for attention deficit disorder with hyperactivity in adolescents. Psychopharmac. Bull. 21, 216-221.

Waizer, J., Hoffman, S. P., Polizos, P. and Engelhardt, D. M. (1974) Outpatient treatment of hyperactive schoolchildren with imipramine. Am. J. Psychiat. 131, 587-591.

WEBER, K. (1985) Methylphenidate: rate dependent drug effects in hyperactive boys. Psychopharmac. 85, $231-235$.

Weingartner, H., LANGer, D., Grice, J. and Rapoport, J. L. (1982) Acquisition and retrieval of information in amphetamine-treated hyperactive children. Psychiat. Res. 6, 21-29.

Weingartner, H., Rapoport, J. L., Buchsbaum, M. S. Bunney, W. E., Ebert, M. H., Mikkflsen, E. J. and CAINES, E. D. (1980) Cognitive processes in normal and hyperactive children and their response to amphetamine treatment. J. abnorm. Psychol. 89, 25-37.

Weiss, G. (1985) Follow-up studies on outcome of hyperactive children. Psychopharmac. Bull. 21, $169-177$.

Weiss, G. and Hechtman, L. (1979) The hyperactive child syndrome. Science 205, 1348-1354.

WeNDER, P. H. (1971) Minimal Brain Dysfunction in Children. J. Wiley: N.Y.

WENDER, P. H. (1976) Hypothesis for a possible biochemical basis of minimal brain dysfunction. In: Neuropsychology of Learning Disorders. Eds. R. M. KNIGHTS and D. J. BAKER. University Park Press: Baltimore.

Wender, P. H., WoOD, D. and ReIMHerr, F. (1984) Studies in attention deficit disorder, residual type (minimal brain dysfunction in adults). Psychopharmac. Bull. 21, 18-20.

Wender, P. H., Wood, D. R. and ReimherR, F. W. (1985a) Pharmacological treatment of attention deficit disorder, residual type (ADD:RT, "minimal brain dysfunction", "hyperactivity") in adults. Psychopharmac. Bull. 21, 222-231.

Wender, P. H., EPSTEIN, R. S., Kopin, I. J. and Gordon, E. K. (1971) Urinary monoamine metabolites in children with minimal brain dysfunction. Am. J. Psychiat. 127, 1411-1415.

Wender, P. H., ReIMHerR, F. W., Wood, D. and WARD, M. A. (1985b) A controlled study of methyiphenidate in the treatment of attention deficit disorder with hyperactivity, residual type, in adults. Am. J. Psychiat. $142,542-552$.

Wender, P. H., Wood, D. R., Reimherr, F. W. and WARD, M. A. (1983) An open trial of pargyline in the treatment of attention deficit disorder, residual type. Psychiat. Res. 9, 329-336.

WERRY, J. S. (1968) Studies on the hyperactive child: IV, an empirical analysis of the minimal brain dysfunction syndrome. Arch. gen. Psychiat. 19, 9-16.

WerRY, J. S. and AMAN, W. G. (1975) Methylphenidate and haloperidol in children: effects on attention, memory and activity. Arch. gen. Psychiat. 32, 790-795.

Weymenmeyer, J. A. and Phillips, M. I. (1982) Angiotensin-like immunoreactivity in the brain of the spontaneously hypertensive rat. Hypertension 4, 514-523.

Whitehorn, D., Atwater, D. G., Low, W. C., Gellis, J. E. and Hendley, E. D. (1983) Independence of blood pressure and locomotor activity in normotensive and genetically hypertensive rat. Behav. neur. Biol. 37, 357-361.

Winsberg, B., Bialer, T., Kupietz, S. and Tobias, J. (1972) Effects of imipramine and dextroamphetamine on behavior of neuropsychiatrically impaired children. Am. J. Psychiat. 128, 1425-1431.

WinsBerg, B. G., KupIETZ, S. S. YePES, L. E. and GoldsteIN. S. (1980) Ineffectiveness of imipramine in children who fail to respond to methylphenidate. J. Aut. Devl Dis. 10, 129-139.

WinTERnitz, S. R., Wyss, J. M. and OPARIL, S. (1984) The role of the posterior hypothalamic area in the pathogenesis of hypertension in the spontaneously hypertensive rat. Brain Res. 324, 51-58.

Wolf, M. E. and Mosnalm, A. D. (1983) Phenylethylamine in neuropsychiatric disorders. Gen. Pharmac. 14, $385-390$.

Wolf, W. A., Kuhn, D. M. and Lovenberg, W. (1981) Pressor effects of dorsal raphe stimulation and intrahypothalamic application of serotonin in the spontaneously hypertensive rat. Brain Res. 208, 192-197.

WoOd, D. R., ReImherR, F. W. and Wender, P. H. (1985) Amino acid precursors for the treatment of attention deficit disorder, residual type. Psychopharmac. Bull. 21, 146-149. 
Wright, J. W., Sullivan, M. J. and Harding, J. W. (1985) Dysfunction of central angiotensinergic aminopeptidase activity in spontaneously hypertensive rats. Neurosci. Letts 61, 351-356.

Wu, J. J., SHIH, C-J. and LIN, M-T. (1984) Tachycardia, hypertension and decreased reflex bradycardia produced by striatal lesions induced by kainic acid. Neuropharmac. 23, 1231-1235.

YAmor, Y., Matsumoto, M., Yamabe, H. and Okamoto, K. (1969) Augmentation of spontaneous hypertension by chronic stress in rats. Jap. Circul. J. 33, 399-409.

ZAHN, T. P., RAPOPORT, J. L. and THOMPSON, T. P. (1980) Autonomic and behavioral effects of dextroamphetamine and placebo in normal and hyperactive prepubertal boys. J. abnorm. Child. Psychol. 8, 145-160.

Zametkin, A. J., Karoum, F., Linnolla, M., Rapoport, J. L., Brown, G. L., Chuang, L-W. and Wyatt, R. J. (1985) Stimulants, urinary catecholamines and indoleamines in hyperactivity. Arch. gen. Psychiat. 42, 251-255.

Zinı, I., Pich, E. M., Fuxe, K., Lenzi, P. L., Agnati, L. F., Harfstrand, A., Mutt, V., Tatemoto, K. and Moscara, M. (1984) Actions of centrally administered neuropeptide $Y$ on EEG activity in different rat strains and in different phases of their circadian cycle. Acta physiol. scand. 122, 71-77. 